\title{
Flow of Bi-modal Slurry through Horizontal Bend ${ }^{\dagger}$
}

\author{
Deo Raj Kaushal ${ }^{1 *}$, Arvind Kumar ${ }^{2}$, Yuji Tomita ${ }^{3}$, \\ Shigeru Kuchii ${ }^{4}$ and Hiroshi Tsukamoto ${ }^{4}$ \\ ${ }^{1}$ Department of Civil Engineering, IIT Delhi, India \\ ${ }^{2}$ Department of Mechanical Engineering, YMCA UST, India \\ ${ }^{3}$ Kyushu Institute of Technology, Japan \\ ${ }^{4}$ Kitakyushu National College of Technology, Japan
}

\begin{abstract}
Extensive experimental investigations were carried out for pressure drop and concentration profile in the flow of bi-modal slurry comprising silica sand and fly ash with mean diameter of 450 and $75 \mu \mathrm{m}$, respectively, at six silica sand:flyash ratios (namely, 100:0, 90:10, 80:20, 70:30, 60:40 and 0:100) in a $53 \mathrm{~mm}$ diameter horizontal bend. Flow velocity was varied up to $3.56 \mathrm{~m} / \mathrm{s}$ (namely, $1.78,2.67$ and $3.56 \mathrm{~m} / \mathrm{s}$ ) at two efflux concentrations of $8.82 \%$ and $16.28 \%$ for each silica sand:flyash ratio. The experimental data were compared with the CFD modelling results using an Eulerian two-phase model available in the FLUENT software. Eulerian model predicted almost all the experimental data collected in the present study for pressure drop and concentration profile with fair accuracy. The bend loss coefficient $k_{\mathrm{t}}$ was found to decrease with increase in percentage of flyash for silica sand:flyash ratio up to 70:30. Further increase in flyash did not show any significant change in the value of $k_{\mathrm{t}}$.
\end{abstract}

Keywords: Eulerian model, CFD modelling, Bi-modal slurry, pipe bend, pressure drop, concentration profile

\section{Introduction}

Transportation of granular solids in slurry form through pipeline is widely applied in industries due to its several inherent advantages, such as, continuous delivery, flexible routing, ease in automation and long distance transport capability. Slurry pipelines are used for transportation of mineral ore, coal, flyash and tailings materials. In dredging operations, sand dredged from rivers is often pumped with water through a pipeline to a construction site. The flow mechanism of slurry transport through pipeline is of vital importance to the designers of slurry transport system. Pipeline bends normally incur relatively higher pressure drop and are prone to excessive erosion compared to the straight equivalent length of pipe. Flow in bends is quite complex and complexity is further increased for two-phase mixtures. Studies available in literature have shown that the flow in bends for solid-liquid mixture system is much more complicated than in gas-

\footnotetext{
Received 18 January 2016; Accepted 20 July 2016

J-STAGE Advance Publication online 30 August 2016

Hauz Khas, New Delhi-110016, India

Faridabad, Haryana, India

1-1 Sensui cho, Tobata, Kitakyushu 804-8550, Japan

5-20-1 Shii, Kokura-minami, Kitakyushu 802-0985, Japan

* Corresponding author: Deo Raj Kaushal;

E-mail:kaushal@civil.iitd.ac.in

TEL: +91-98-1828-0867 FAX: +91-11-2658-1117
}

solid system (Kumar, 2010). Reported literature for solidliquid flow in bends is limited which may be due to complexities involved. It is already well established that bends in general are prone to excessive erosion wear and hence need frequent replacements resulting in shut-downs of plants leading to loss of man hours. In order to increase the longevity of the pipe bends and to minimise the pressure loss through bends, a detailed knowledge of the flow properties in the pipe bends and downstream of the bend is essential. Most of the experimental and computational work related to the effect of bends in slurry pipeline system concern the erosion, concentration profiles and pressure drops for the flow of mono-dispersed particles (Kaushal et al., 2013). However, there is only few studies available on flow of bi-modal and multi-sized particles through pipe bends.

Nasr-El-Din and Shook (1987) have measured the concentration profile and velocity distribution for flow of bimodal slurry in a vertical pipe with short and long radius bends. They observed axi-symmetric flow for short radius bend whereas the coarser and finer particles migrate towards the outer and inner wall, respectively, for the long radius bend. Ahmed et al. (1994) have measured the pressure drop in a $90^{\circ}$ horizontal bend using two multi-sized particulate slurries namely iron ore and zinc tailings slurries. From their studies they concluded that the presence of the finer particles reduces the additional pressure drop in the flow of multi-sized particulate slurries across the 
borids. Pि fhey found from bi-modal viewpoint that particles reardistribute more in the bend as compared to the straight pipe but could not identify the plane of movement. The extent of re-distribution reduces as the flow velocity and concentration increases. Gupta et al. (1997) confirmed the findings of Ahmed et al. (1994) for multi-sized particulate slurries. They observed the maximum concentration to be at the bottom of the bend along the vertical plane even at higher concentration also. They however observed that largest size particles moved outward and its concentration was higher in outer bottom periphery. The finer particles were observed to be uniformly distributed. Literature on studies of pressure drop by Kazanskij and Hinsch (1974), Boothroyde et al. (1979), Hayashi et al. (1980) and Verkerk (1982) reveals that mixing of fine particles in small percentage up to $20-30 \%$ in coarse slurry helps to reduce the pressure drop and makes the distribution of particles homogeneous.

Advent of highly sophisticated computers with advanced numerical techniques involved in computational fluid dynamics (CFD) analysis made it possible to analyse the operation of slurry transport systems using numerical simulations but the literature review clearly reveals that the application of CFD for such systems is few (Thinglas and Kaushal, 2008a, 2008b). Kaushal et al. (2012) numerically simulated using mixture and granular-Eulerian twophase models for mono-dispersed high concentrate slurry flow in Pipeline. Standard k- $\varepsilon$ model per phase and the standard wall function with no slip were used. They concluded that mixture model failed to predict but granularEulerian model per phase gave better predictions for pressure drop at all efflux concentrations and flow velocities. However, this model failed to predict solid concentration distribution, more dominantly at higher concentrations and flow velocities, for few experimental data near the pipe bottom. Kaushal et al. (2013) made use of Eulerian model in FLUENT software to calculate the pressure drop and concentration profile in mono-dispersed silica sand slurry flow through pipe bend. Eulerian model was found reasonably effective with the slurry pipe bend on the basis of good agreement between their experimental and computational results. Messa and Malavasi (2014) simulated the fully-suspended slurry flow in horizontal pipe based on the standard k- $\varepsilon$ model. Phase diffusion fluxes are introduced in all conservation equations to reproduce the effect of the turbulent dispersion of particles. The mixture viscosity approach is employed to model the effect of the presence of multiple particles on interfacial momentum transfer. Equilibrium wall function for smooth walls is applied to both phases and no slip is assumed between the phases at the inlet section. In comparison with similar models, the authors revealed that the used model showed better performance in terms of numerical efficiency, quality of the solution and range of applicability. Gopaliya and
Kaushal (2015) investigated the effects of particle size on slurry flow parameters using CFD by implementing granular RNG $k-\varepsilon$ turbulence model with standard wall function and no-slip at the wall. It is reported that high deviations in the values between simulated and experimental data of local solid concentration values are observed in the lower half of the cross-section just near the wall for coarser grain sizes. Gopaliya and Kaushal (2016) analysed the effects of particle size on various slurry flow parameters such as pressure drop, solid phase velocity distribution, friction factor, granular pressure, turbulent viscosity, turbulent kinetic energy and its dissipation. However, there is no study available in literature for modelling the flow of bi-modal or multi-sized particulate slurries through pipeline using three-dimensional CFD based Eulerian twophase model. The present research work delves deep into the transport mechanism of bi-modal slurries through pipe bend by conducting experiments and numerical simulations.

In the present study, measurements of concentration and particle size distribution are made at downstream of the bend at different locations to understand the phenomena of re-distribution of particles belonging to two size fractions of the bi-modal slurry. Concentration profiles and pressure drops are modelled using Eulerian model in a pipe bend for the flow of bi-modal silica sand and fly ash slurries at six silica sand:flyash ratios. The CFD based modelling results are compared with the experimental data.

\section{Experimental setup}

In the present study, pilot plant test loop having inside diameter of $53 \mathrm{~mm}$ and length of $30 \mathrm{~m}$ is used. Pipe bend is laid horizontally in the loop. Fig. 1 shows the schematic layout of the pilot plant test loop. The loop is described in detail by Kumar (2010) Kaushal et al. (2013).

We measured concentration profiles by sampling tube in the mid-vertical plane in the downstream of bend exit as shown in Fig. 2 Sampling tube was having a $4 \mathrm{~mm} \mathrm{x}$ $6 \mathrm{~mm}$ rectangular slot $2 \mathrm{~mm}$ above the end to collect representative samples in the pipe line. Samples are collected from different heights from bottom of the pipe in the vertical plane of the cross-section to measure the concentration profile under near isokinetic conditions. As the flow is under pressure, slurry comes out from the sampling tube with the same velocity and volumetric concentration as it is flowing in the pipeline at the location of measurement. During the collection of samples it is ensured that the flow of the slurry through the sampling tube outlet is nonstop and uniform. At the end of the pipe loop a sampling point is provided in the vertical portions to collect an average efflux sample. The size of rectangular opening 


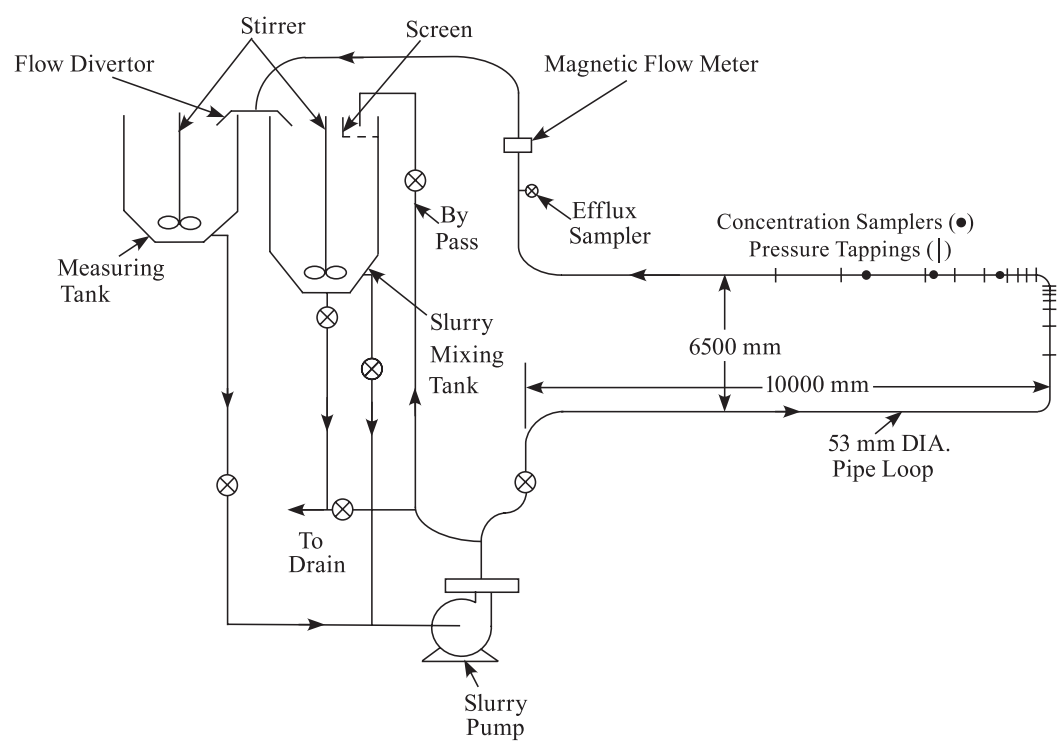

Fig. 1 Schematic diagram of pilot plant test loop.

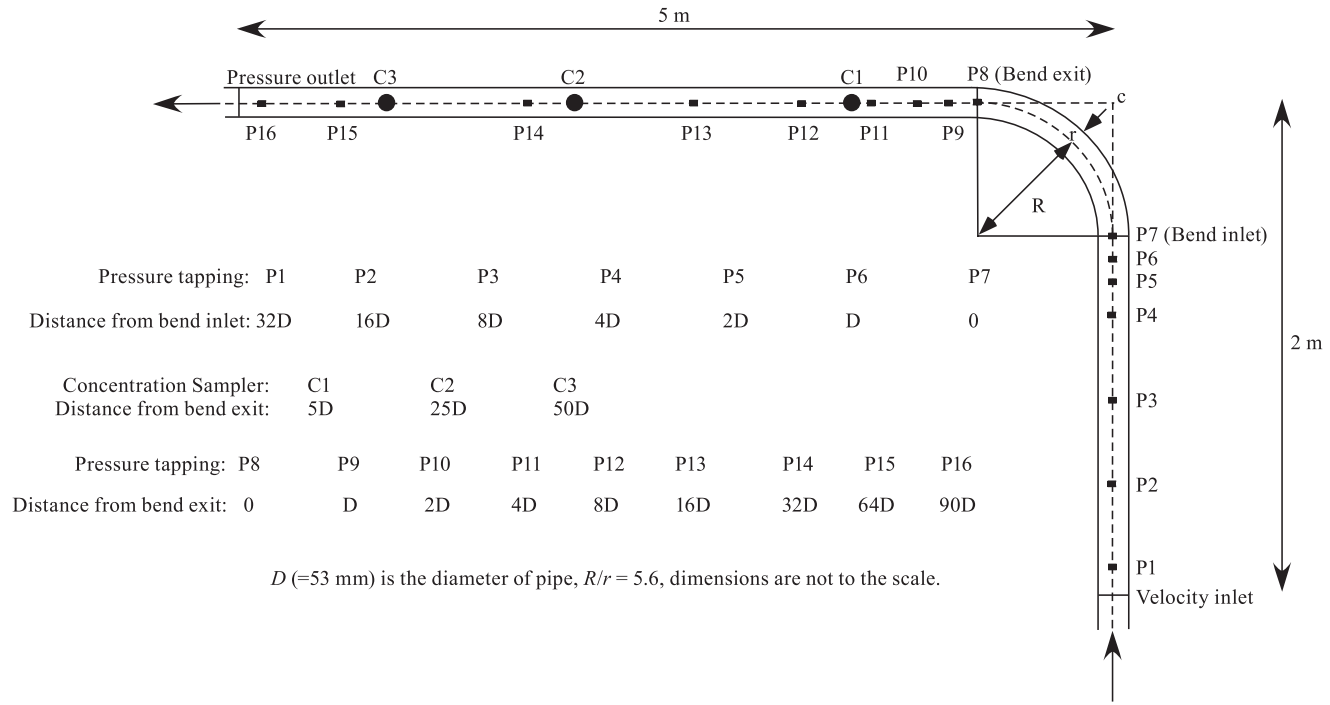

Fig. 2 Locations of pressure tappings and concentration samplers

was optimized after extensive trials to ensure smooth flow of slurry. The accuracy of the sampling tube is checked by integrating the measured concentration profile to obtain overall concentration and comparing it with the measured efflux concentration. An error included in the measurement was found to be $\pm 1 \%$. This error may be attributed to the slip velocity between primary water phase and secondary silica sand or fly ash phase. The bend geometry used in the simulations was identical to that of bend used in experiments. The bend was horizontally laid in $(x, y)$ plane. In the present study, concentration samples are collected from six different locations for each experimental run by traversing the sampling probe in the mid-vertical plane of pipe cross-section located at $z^{\prime}=0.094,0.189,0.377,0.566,0.755$ and 0.943 , where $z^{\prime}=z / D$. Three sampling probes located at $5 D, 25 D$ and $50 D$ from bend exit are used for collecting such concentration samples (Fig. 2). Overall volumetric concentrations $\alpha_{\mathrm{s}}$ are experimentally measured for each run, where susbscript "s" represents the slurry. The slurry samples are dried in oven and sieved to determine the concentrations of silica sand $\left(\alpha_{\mathrm{ss}}\right)$ and flyash $\left(\alpha_{\mathrm{f}}\right)$ considering $\alpha_{\mathrm{s}}=\alpha_{\mathrm{ss}}+\alpha_{\mathrm{f}}$. A sieve of aperture diameter of 150 micron is used to separate out silica sand and flyash particles from each dried sample.

Two methods were applied for the flow rate measurement (measuring tank and electro-magnetic flow meter) in this study as shown in Fig. 1. Magnetic flow meter was also used in adjusting the flow velocity to the desired value. The accuracy of flow rate measurement by electro- 
Table $\mathrm{K}^{\circ}$ Details of pipe bend used in the present study. $N^{N}$

(a) $R / r$ and length of bend

\begin{tabular}{ccc}
\hline $\begin{array}{c}\text { Radius of } \\
\text { curvature }(R)\end{array}$ & $\begin{array}{c}\text { Radius ratio } \\
(R / r)\end{array}$ & $\begin{array}{c}\text { Length of } \\
\text { pipe bend }\end{array}$ \\
\hline $148.4 \mathrm{~mm}$ & 5.6 & $4.40 \mathrm{D}$ \\
\hline
\end{tabular}

(b) Inside radius of pipe bend: $r=26.5 \mathrm{~mm}$

(c) $D=$ Pipe diameter $=53 \mathrm{~mm}$

(d) $k_{\mathrm{s}}=0.15 \mathrm{~mm}$ and $k_{\mathrm{s}} / D=0.0003$

magnetic flow meters is of the order of $\pm 0.5 \%$. The calibration of the meters was periodically checked for slurry flows at various concentrations using measuring tank.

Efflux sampler is used to monitor the efflux concentration as shown in Fig. 1. If we consider the concentration profile in vertical section of pipeline as uniform across the pipe cross-section and $V_{\mathrm{ss}}=V_{\mathrm{f}}=V_{\mathrm{w}}=V_{\mathrm{sl}}=V_{\mathrm{m}}$, the efflux concentration $\left(C_{\mathrm{vf}}\right)$ of slurry may be defined as $C_{\mathrm{vf}}=C_{\mathrm{ss}}+C_{\mathrm{f}}$, where $C_{\mathrm{ss}}$ and $C_{\mathrm{f}}$ is the efflux concentration of silica sand and flyash, respectively. $C_{\mathrm{ss}}$ and $C_{\mathrm{f}}$ may be mathematically defined as follows:

$$
\begin{aligned}
& C_{\mathrm{ss}}=\frac{1}{A} \int \alpha_{\mathrm{ss}} \mathrm{d} A \\
& C_{\mathrm{f}}=\frac{1}{A} \int \alpha_{\mathrm{f}} \mathrm{d} A
\end{aligned}
$$

Experiments are carried out on rough bend of which geometric details are tabulated in Table 1. Specific gravity of silica sand and flyash is measured experimentally as 2.65 and 2.1, respectively. Silica sand and fly ash particles are having median diameter of $450 \mu \mathrm{m}$ and $75 \mu \mathrm{m}$ with geometric standard deviation of 1.15 and 1.10, critical deposition velocity of $1.5 \mathrm{~m} / \mathrm{s}$ and $1.1 \mathrm{~m} / \mathrm{s}$, respectively. Mixtures having different silica sand:flyash ratios at a particular efflux concentration are prepared by mixing the silica sand and flyash in that ratio by volume.

\section{Mathematical model}

The ranges of Stokes number of particles and Dean number for the pipeline slurry flows carried out in the present study are 0.02 to 2.0 and 33385 to 59152, respectively. The mathematical model implemented is described in Kaushal et al. (2013) and given in Appendix A. Water, silica sand and fly ash are considered as three phases having different properties in the calculations. Water is considered as fluid and primary phase. Silica sand and fly ash are considered as granular and secondary phases with different concentration, particle size and mass densities. Momentum equations have been solved for each phase separately. Other steps in computations are similar to that described in earlier work by Kaushal et al. (2013).

\section{Modeling results}

\subsection{Pressure drop}

The normalized pressure drops at different locations $\left[\Delta h /\left(V_{\mathrm{m}}{ }^{2} / 2 g\right)\right.$, where, $\left.\Delta h=\Delta p /\left(\rho_{\mathrm{m}} g\right)\right]$ are presented in Fig. 3 and 4 for $C_{\mathrm{vf}}=8.82$ and $16.28 \%$ for $70: 30$ silica sand:flyash ratio at $V_{\mathrm{m}}=1.78,2.67$ and $3.56 \mathrm{~m} / \mathrm{s}$.

From Fig. 3 and 4, it is clear that the flow is slightly disturbed before and after the bend. The permanent pressure loss reduces with increase in $V_{\mathrm{m}}$. This reduction is interpreted from the slope of the pressure drop line, upstream and downstream of the bend.

It is observed from Fig. 3 and $\mathbf{4}$ that the pressure drop reduces as the amount of flyash increases. However, the decrease in pressure drop is negligible for amount of

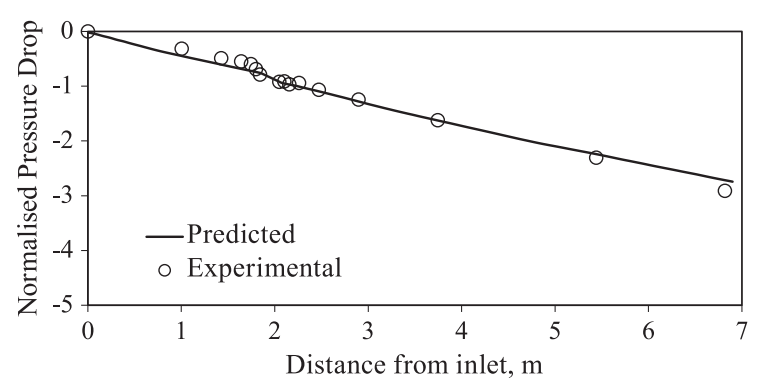

(a) $V_{\mathrm{m}}=1.78 \mathrm{~m} / \mathrm{s}$

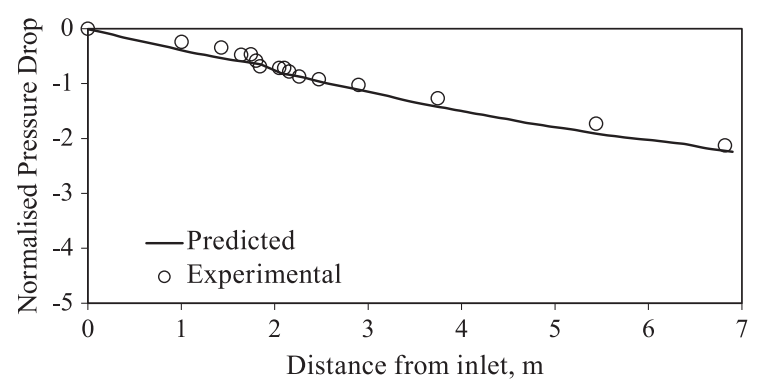

(b) $V_{\mathrm{m}}=2.67 \mathrm{~m} / \mathrm{s}$

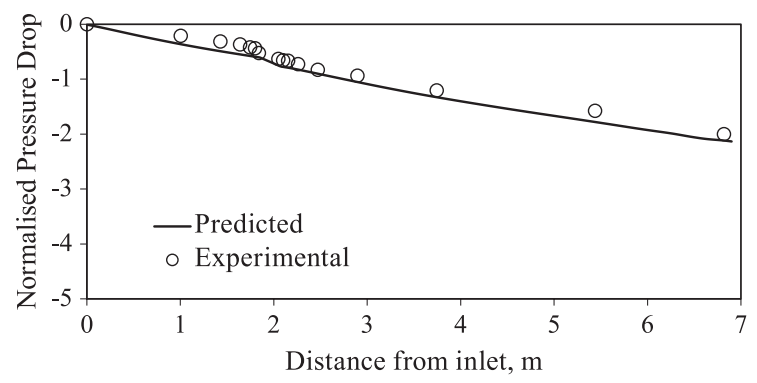

(c) $V_{\mathrm{m}}=3.56 \mathrm{~m} / \mathrm{s}$

Fig. 3 Normalised Pressure drop $\left[\Delta p /\left(\rho_{\mathrm{m}} V_{\mathrm{m}}{ }^{2} / 2\right)\right]$ distributions at different flow velocities at $C_{\mathrm{vf}}=8.82 \%$ (sand:flyash $=70: 30$ ). 
florish thore than $30 \%$.

Nito (1960) has shown that to establish permanent pressure loss across a bend, considerable lengths of the pipe on both sides of the bend have to be included and this is shown schematically in Fig. $\mathbf{5}$ as described below:

i. A-B-C-D-E shows the actual hydraulic gradient.

ii. A-B'-C'-D'-E' shows hydraulic gradient in a corresponding straight pipe.

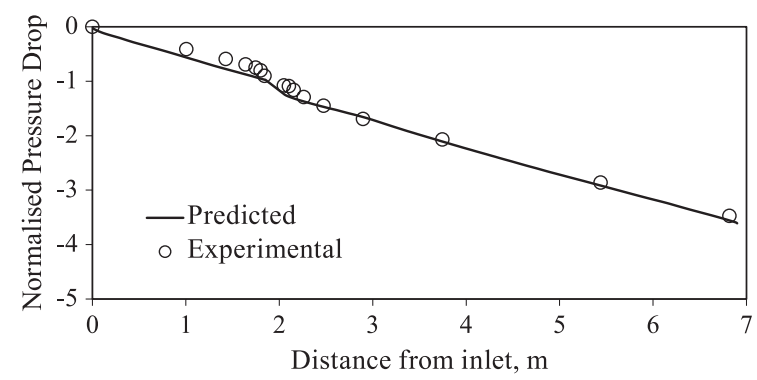

(a) $V_{\mathrm{m}}=1.78 \mathrm{~m} / \mathrm{s}$

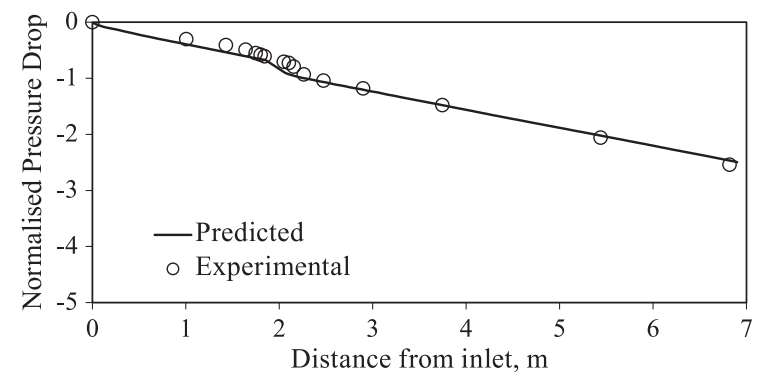

(b) $V_{\mathrm{m}}=2.67 \mathrm{~m} / \mathrm{s}$

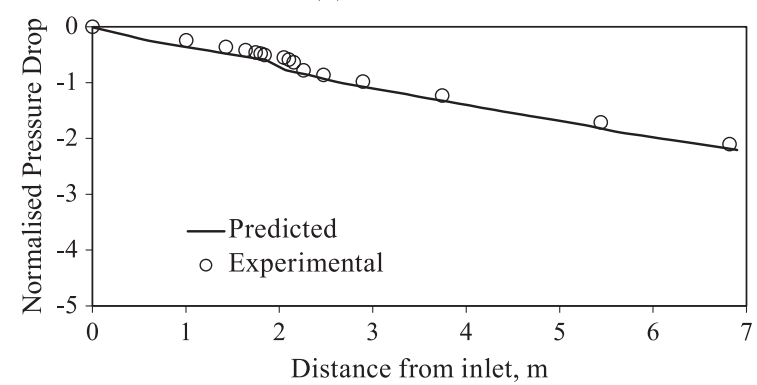

(c) $V_{\mathrm{m}}=3.56 \mathrm{~m} / \mathrm{s}$

Fig. 4 Normalised Pressure drop $\left[\Delta p /\left(\rho_{\mathrm{m}} V_{\mathrm{m}}{ }^{2} / 2\right)\right]$ distributions at different flow velocities at $C_{\mathrm{vf}}=16.28 \%$ (sand:flyash $=70: 30$ ).

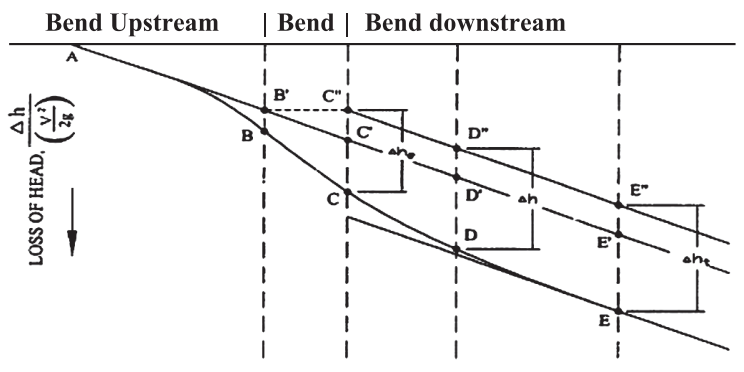

Fig. 5 Typical hydraulic gradient in pipe flow in the presence of bend. iii. A-B'-C"-D"-E" shows hydraulic gradient without pipe bend or when the pipe bend is removed. It is clear from these hydraulic grade lines that total head loss across the pipe bend is $\Delta h_{\mathrm{t}}$.

iv. The total bend loss coefficient $\left(k_{\mathrm{t}}\right)$ is defined as

$$
k_{\mathrm{t}}=\frac{\Delta h_{t}}{\left(\frac{V_{m}{ }^{2}}{2 g}\right)}
$$

The measured and simulated bend loss coefficients $\left(k_{\mathrm{t}}\right)$ are evaluated for each run as and are shown graphically in Fig. 6 and 7 for $C_{\mathrm{vf}}=8.82 \%$ and $16.28 \%$ as a function

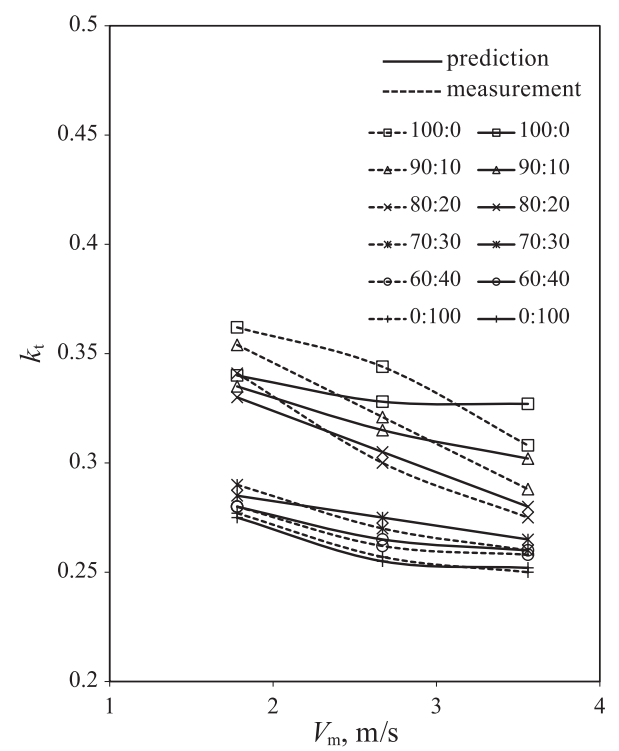

Fig. 6 Measured and predicted bend loss coefficient $\left(k_{t}\right)$ at $C_{\mathrm{vf}}=8.82 \%$ for various sand:flyash ratios.

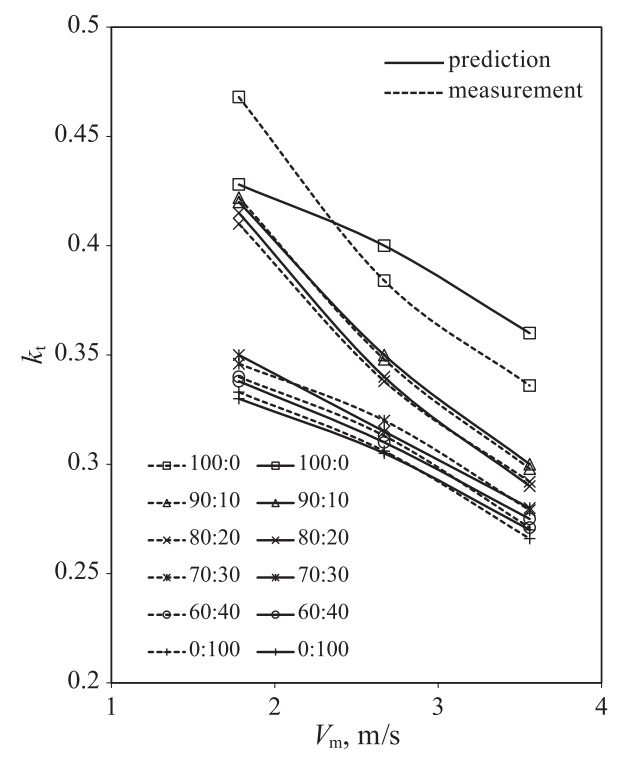

Fig. 7 Bend loss coefficient $\left(k_{\mathrm{t}}\right)$ at $C_{\mathrm{vf}}=16.28 \%$ for various sand:flyash ratios. 


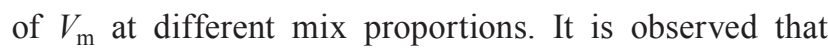
value of $k_{\mathrm{t}}$ increases as $C_{\mathrm{vf}}$ increases. Value of $k_{\mathrm{t}}$ reduces as flow velocity increases for all sand:flyash ratios and efflux concentrations. However, the rate of this reduction decreases with increase in amount of flyash. A reduction in total bend loss coefficient is seen with increase in the flyash mixed in the bi-modal slurry up to 70:30. However, further increase in flyash do not show any significant change in the value of $k_{\mathrm{t}}$. The uniform distribution of fine particles, that is flyash, across the pipe for the bi-modal slurry provides a uniform suspension of increased viscosity for the coarse particles. This uniform suspension of finer particles provides better suspension to coarse particles resulting into the reduced pressure drop. At the lowest velocity, appreciably high value of $k_{\mathrm{t}}$ is obtained for all the mix proportions when compared to that obtained at lower concentration. Fig. 6 and 7 also show that the CFD modeling gives good predictions with error of $\pm 10 \%$. (a) Sand

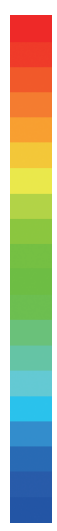

0.27

0.23

0.18

0.13

0.089

0.053

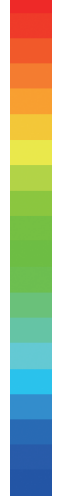

049

(b) Flyash

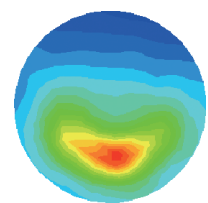

(i) bend inlet

0.044

0.04

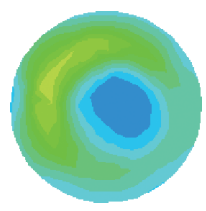

(iv) $X=5 D$

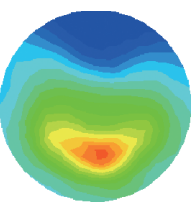

(i) bend inlet

(c) Mixture

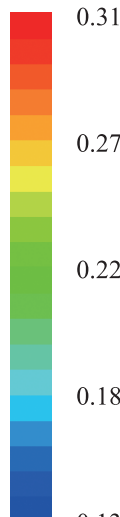

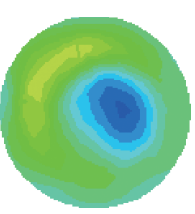

(iv) $X=5 D$

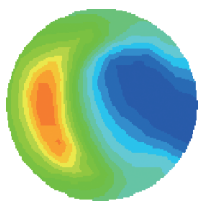

(ii) bend centre

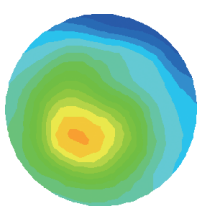

(v) $X=25 D$

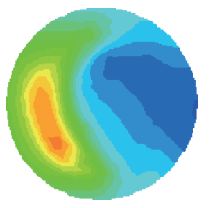

(ii) bend centre

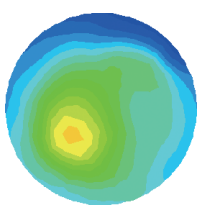

(v) $X=25 D$

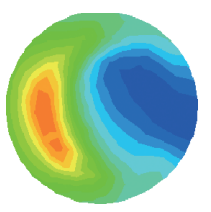

(ii) bend centre

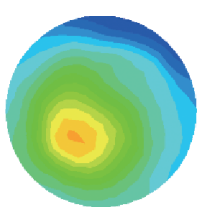

(v) $X=25 D$

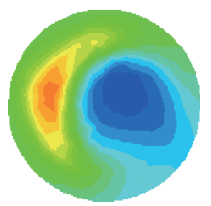

(iii) bend exit

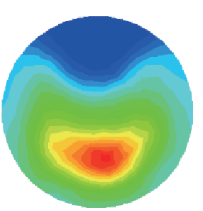

(vi) $X=50 D$

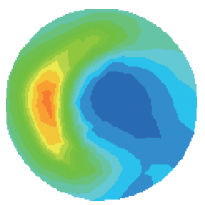

(iii) bend exit

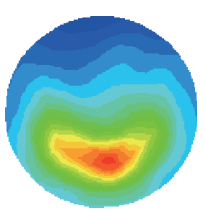

(vi) $X=50 D$

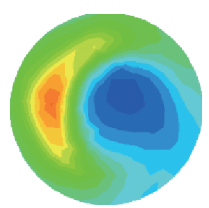

(iii) bend exit

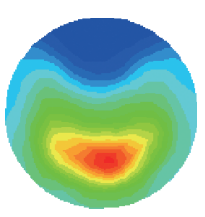

(vi) $X=50 D$

Fig. 8 Cross-sectional concentration distributions of (a) $\alpha_{\mathrm{ss}}$, (b) $\alpha_{\mathrm{f}}$ and (c) $\alpha_{\mathrm{s}}$ in fraction at different locations for sand:flyash $=70: 30$ at $V_{\mathrm{m}}=3.56 \mathrm{~m} / \mathrm{s}$ and $C_{\mathrm{vf}}=16.28 \%$. 
In the present study, the turbulent viscosity at bend outletwis $0.151,0.268$ and $0.305 \mathrm{~kg} / \mathrm{m}-\mathrm{s}$ for $C_{\mathrm{vf}}=16.28 \%$ at $V_{\mathrm{m}}=1.78,2.67$ and $3.56 \mathrm{~m} / \mathrm{s}$, respectively. Turbulent viscosity at bend outlet is $0.056,0.230$ and $0.307 \mathrm{~kg} / \mathrm{m}-\mathrm{s}$ for $C_{\mathrm{vf}}=8.82 \%$ at $V_{\mathrm{m}}=1.78,2.67$ and $3.56 \mathrm{~m} / \mathrm{s}$, respectively.

\subsection{Concentration distribution}

Cross-sectional concentration distributions of silica sand $\left(\alpha_{\mathrm{ss}}\right)$, flyash $\left(\alpha_{\mathrm{f}}\right)$ and mixture $\left(\alpha_{\mathrm{s}}\right)$ for different silica sand:flyash ratios are calculated using CFD based FLUENT (2006) software. One of such concentration distributions $\alpha_{\mathrm{ss}}, \alpha_{\mathrm{f}}$ and $\alpha_{\mathrm{s}}$ for silica sand:flyash ratio of 70:30 at $C_{\mathrm{vf}}=16.28 \%$ and $V_{\mathrm{m}}=3.56 \mathrm{~m} / \mathrm{s}$ is shown in Fig. 8(a), (b) and (c) for silica sand, fly ash and mixture, respectively. The particles are forced outwards in the vicinity of bend due to the interaction of centrifugal force and pressure driven secondary flows. In a curved flow, there appears a centrifugal force and in order to balance this force pressure increases outward. However, near the wall, fluid velocity is negligibly small and there appears pressure driven flow near the wall inward, thus, secondary flow appears.

Flyash particles are forced outwards along with the silica sand particles (Fig. 8). However, Nasr-El-Din and Shook (1987) observed experimentally that coarser particles $(0.45 \mathrm{~mm}$ diameter $)$ moving towards the outer and finer particles moving towards the inner edge for long radius bend.

The concentration profiles at bend inlet, $X=25 D$ and $50 D$ shows maximum concentration away from bottom of the pipeline at lower velocities for lower concentration and at all velocities for higher concentration. In Fig. 9, distributions of $v_{\mathrm{fz}}, v_{\mathrm{sz}}$ and $v_{\mathrm{ssz}}$ in $\mathrm{m} / \mathrm{s}$ at $C_{\mathrm{vf}}=16.28 \%$ and $V_{\mathrm{m}}=3.56 \mathrm{~m} / \mathrm{s}$ are shown. The effect of bend on velocity profiles is more prominent at $X=5 D$. The observations made previously in Fig. 8 are reaffirmed in Fig. 10 showing the $z$-component of velocity for sand, flyash and water. In this figure, very low values of $v_{\mathrm{fz}}(x, y), v_{\mathrm{sz}}(x, y)$ and $v_{\mathrm{ssz}}(x, y)$ at $X=50 D$ indicate vanishing of the secondary flows.

Fig. 11 depicts the direction and magnitude of velocity component in the perpendicular plane for $C_{\mathrm{vf}}=16.28 \%$ and $V_{\mathrm{m}}=3.56 \mathrm{~m} / \mathrm{s}$ at $X=5 D, 25 D$ and $50 D$. This figure reaffirms the observations in earlier figures.

Figs. 12 to 17 present concentration profiles at $X=5 D$, $25 D$ and $50 D$ from bend outlet at $V_{\mathrm{m}}=1.78,2.67$ and $3.56 \mathrm{~m} / \mathrm{s}$ and $C_{\mathrm{vf}}=8.82 \%$ and $16.28 \%$. Normalized concentration is defined as $\frac{\alpha_{\mathrm{ss}}\left(z^{\prime}\right)}{C_{\mathrm{ss}}}$ for silica sand, $\frac{\alpha_{\mathrm{f}}\left(z^{\prime}\right)}{C_{\mathrm{f}}}$ for flyash and $\frac{\alpha_{\mathrm{s}}\left(z^{\prime}\right)}{C_{\mathrm{vf}}}$ for overall slurry. Figs. 12 to 17 shows good resemblance in experimental and CFD values.

Concentration profiles of sand in bimodal (sand:flyash $=70: 30$ ) slurry at $C_{\mathrm{vf}}=8.82 \%$ and $16.28 \%$ are shown in Fig. 18 to 21. It is observed that spread in the solids concentration profiles is the least at $X=5 D$ and the particles are occupied in the entire cross-section of the pipeline. However, the spread in solids concentration profile increases with increasing $X$ to the extent that solids concentration becomes zero at topmost zone in the pipeline at $X=25 D$ and $50 D$. Furthermore, this area of occupancy by

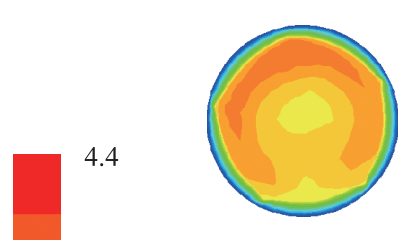

(a) Water at $X=5 D$

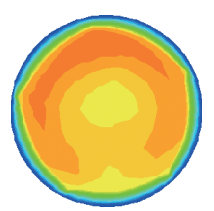

(d) Sand at $X=5 D$

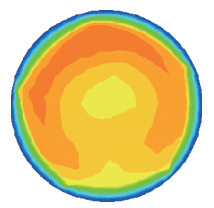

(g) Flyash at $X=5 D$

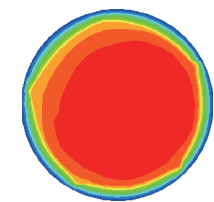

(b) Water at $X=25 D$

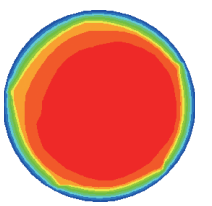

(e) Sand at $X=25 D$

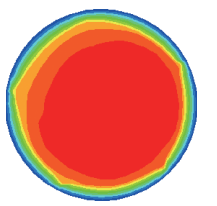

(h) Flyash at $X=25 D$

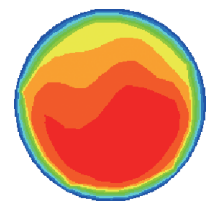

(c) Water at $X=50 D$

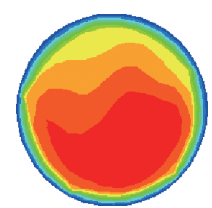

(f) Sand at $X=50 D$

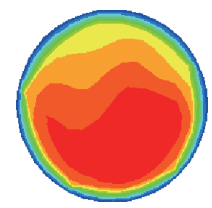

(i) Flyash at $X=50 D$

Fig. 9 Distributions of $v_{\mathrm{fz}}, v_{\mathrm{sz}}$ and $v_{\mathrm{ssz}}$ in $\mathrm{m} / \mathrm{s}$ at $C_{\mathrm{vf}}=16.28 \%$ and $V_{\mathrm{m}}=3.56 \mathrm{~m} / \mathrm{s}$. 
particles increases with increase in velocity of flow.

Nig. 19 shows predicted mid-vertical concentration profiles of sand, in monodispersed (sand:flyash $=100: 0$ ) slurry measured by Kaushal et al. (2013) and in bimodal slurry (sand:flyash $=70: 30$ ) at different $X$ and $V_{\mathrm{m}}$ at $C_{\mathrm{vf}}=8.82 \%$. Asymmetry in the concentration profiles for bi-modal slurry is less. Such a reduction in asymmetry may be attributed to the uniform distribution of flyash across the pipe in the bi-modal slurry, which provides a uniform suspension of increased viscosity and less asymmetric mid-vertical solids concentration profile for the coarse particles. Figs. 20 and 21 reaffirms the fact that re-distribution of solid particles takes place downstream of the bend. This effect decays with increase in distance from bend.

\section{Conclusions}

Following conclusions are drawn the present study:

a. Pressure drop for bi-modal mixture of silica sand and flyash having particle diameter $450 \mu \mathrm{m}$ and $75 \mu \mathrm{m}$, respectively, is found to be less than that of monodispersed (silica sand) slurry flow. In bi-modal slurry flow, the bend loss coefficient $\left(k_{\mathrm{t}}\right)$ decreases with increase in percentage of flyash up to silica sand:flyash ratio of 70:30. Further increase in flyash does not show any significant change in the value of $k_{\mathrm{t}}$.

b. CFD based Eulerian two-phase model predicts pressure drops with fair accuracy (within percentage error of $\pm 10 \%$ ) for the flow of bi-modal slurry in the efflux concentration upto $16.28 \%$ at flow velocities ranging from 1.78 to $3.56 \mathrm{~m} / \mathrm{s}$.
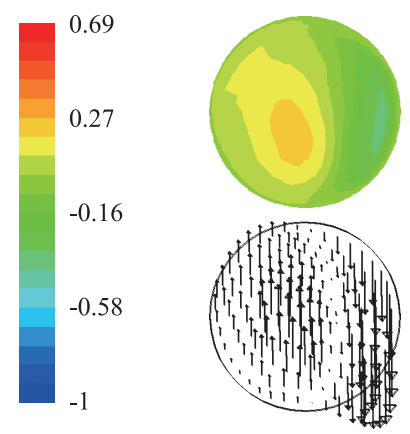

(a) Water at $X=5 D$
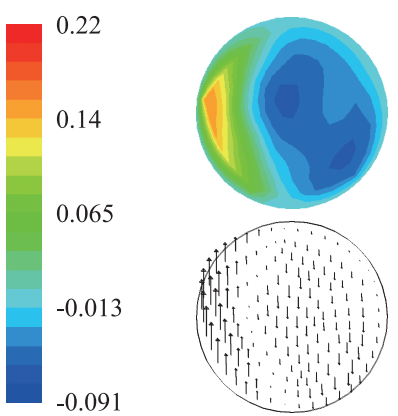

(d) Water at $X=25 D$
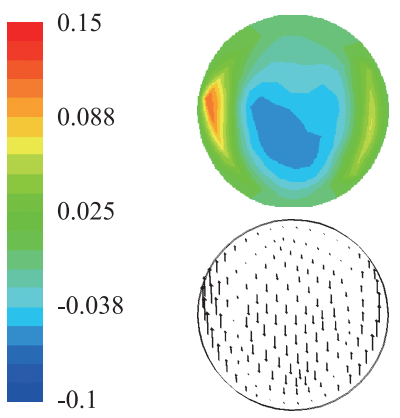

(g) Water at $X=50 D$
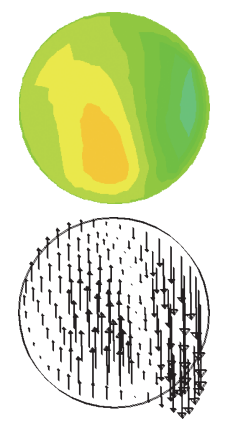

(b) Sand at $X=5 D$
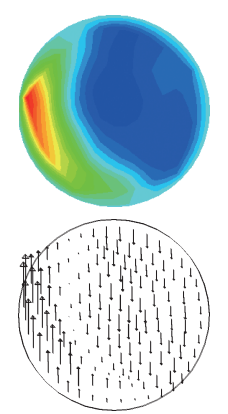

(e) Sand at $X=25 D$
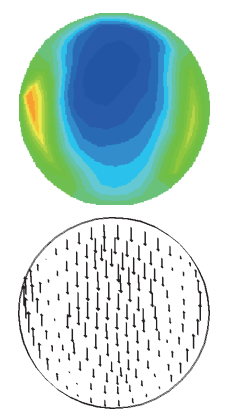

(h) Sand at $X=50 D$
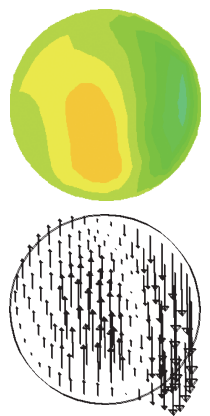

(c) Flyash at $X=5 D$
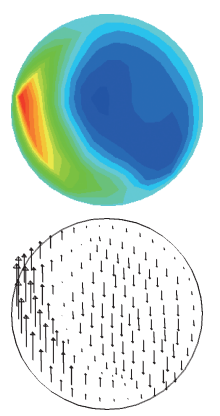

(f) Flyash at $X=25 D$
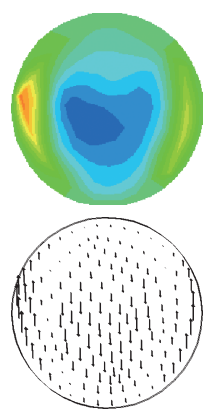

(i) Flyash at $X=50 D$

Fig. 10 Vertical velocity $v_{\mathrm{fz}}(x, y), v_{\mathrm{sz}}(x, y)$ and $v_{\mathrm{ssz}}(x, y)$ at different locations for sand:flyash $=70: 30 \mathrm{in} \mathrm{m} / \mathrm{s}$ for $C_{\mathrm{vf}}=16.28 \%$ and $V_{\mathrm{m}}=3.56 \mathrm{~m} / \mathrm{s}$. 
godegneentratio

stream of bend near the bend exit.

d. The uniform distribution of fine particles across the pipe for the bi-modal slurry provides a uniform suspension of increased viscosity for the coarse particles. This uniform suspension of finer particles provides better suspension to coarse particles, which in turn make the re-distribution of particles after the bend exit at a much faster rate.

e. Redistribution of particles take place in the downstream of the bend. The effect of bend is seen in the downstream of bend near the exit, and this effect de- cays with increase in distance.

f. Asymmetry in the mid-vertical solids concentration profiles for bi-modal (sand:flyash $=70: 30$ ) is less than the mono-dispersed (sand:flyash $=100: 0$ ) particulate slurry.

g. More work needs to be performed to expand the CFD based Eulerian two-phase model for more complex slurries containing particles with broad or multimodal size distributions. Also work should be done to determine how best to deal with slurries containing different species of particles with multiple densities.
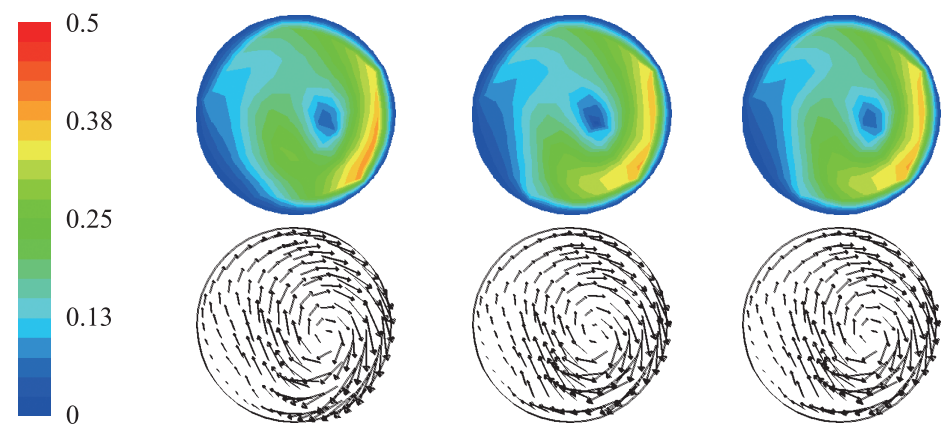

(a) Water at $X=5 D$

(b) Sand at $X=5 D$

(c) Flyash at $X=5 D$
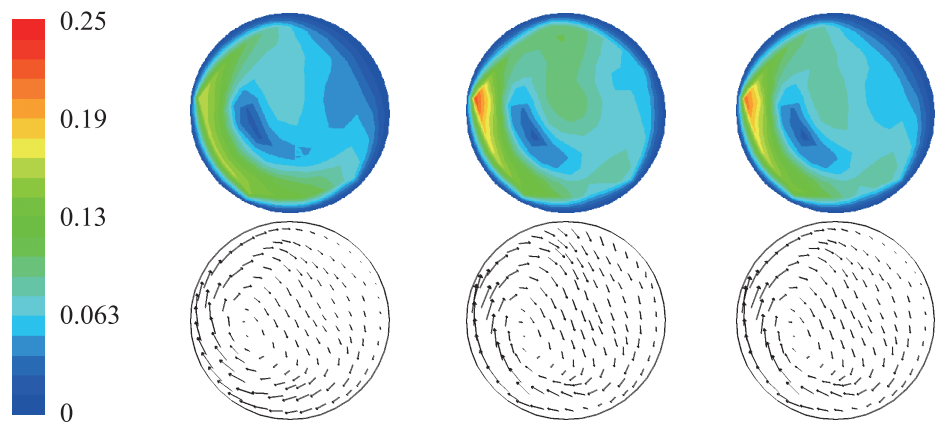

(d) Water at $X=25 D$

(e) Sand at $X=25 D$

(f) Flyash at $X=25 D$
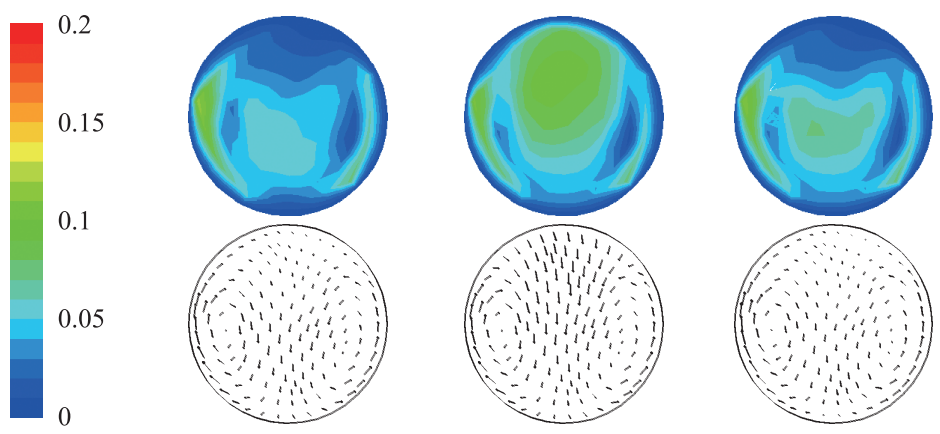

(g) Water at $X=50 D$

(h) Sand at $X=50 D$

(i) Flyash at $X=50 D$

Fig. 11 Perpendicular velocity component at different locations for sand:flyash $=70: 30 \mathrm{in} \mathrm{m} / \mathrm{s}$ for $C_{\mathrm{vf}}=16.28 \%$ and $V_{\mathrm{m}}=3.56 \mathrm{~m} / \mathrm{s}$. 


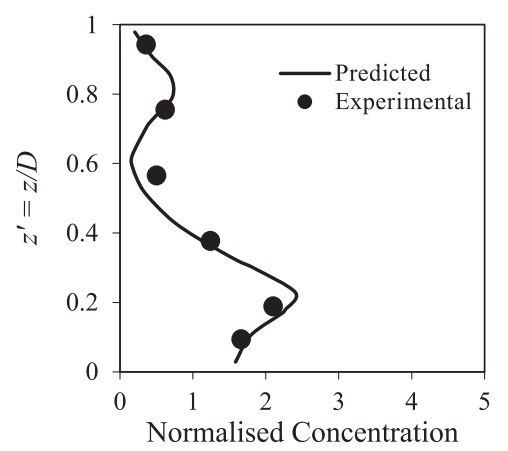

(a) Sand at $X=5 D$

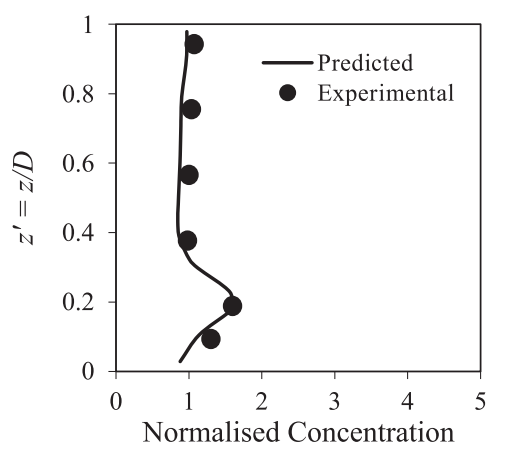

(d) Flyash at $X=5 D$

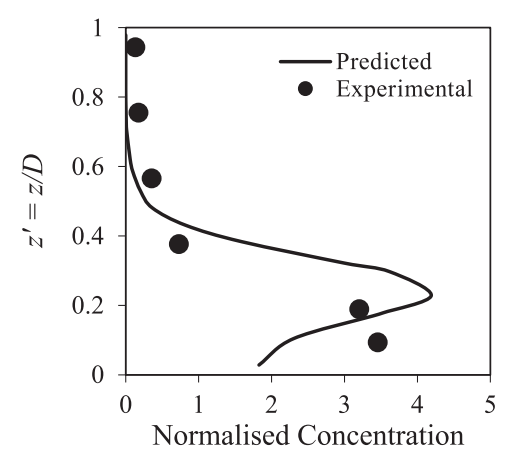

(b) Sand at $X=25 D$

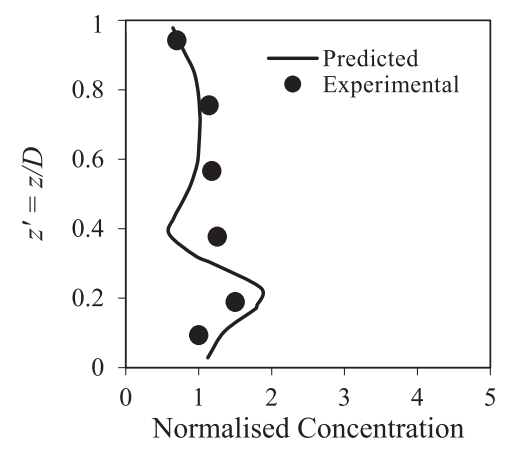

(e) Flyash at $X=25 D$

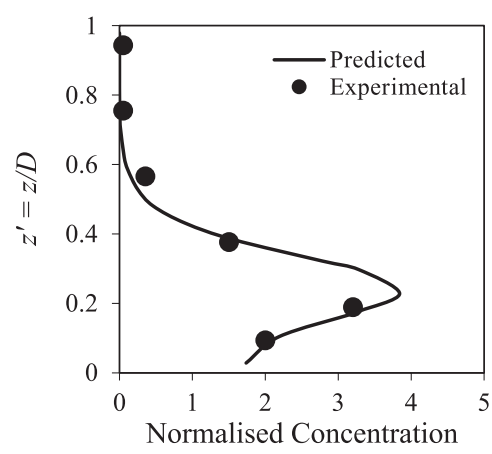

(c) Sand at $X=50 D$

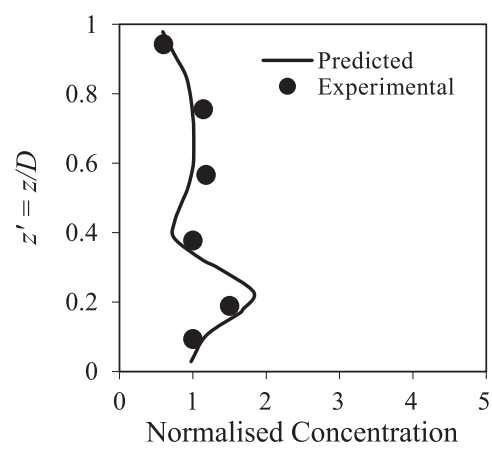

(f) Flyash at $X=50 D$

Fig. 12 Concentration distributions at $C_{\mathrm{vf}}=8.82 \%$ (sand:flyash $\left.=70: 30\right)$ and $V_{\mathrm{m}}=1.78 \mathrm{~m} / \mathrm{s}$ (Normalised Concentration for sand $\left.=\alpha_{\mathrm{s}}\left(z^{\prime}\right) / C_{\mathrm{ss}}\right)$ and Normalised Concentration for fly ash $\left.=\alpha_{\mathrm{f}}\left(z^{\prime}\right) / C_{\mathrm{f}}\right)$.

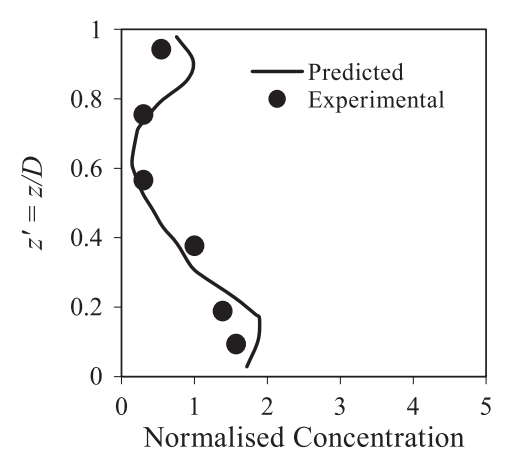

(a) Sand at $X=5 D$

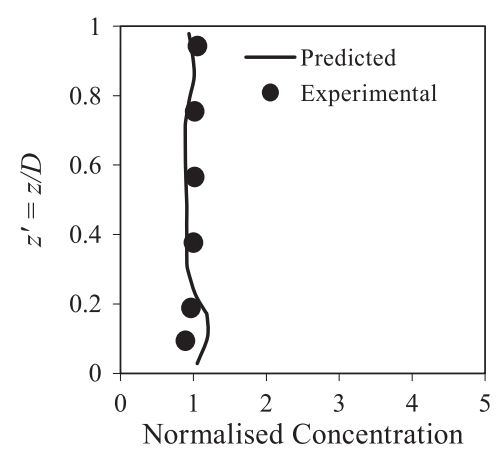

(d) Flyash at $X=5 D$

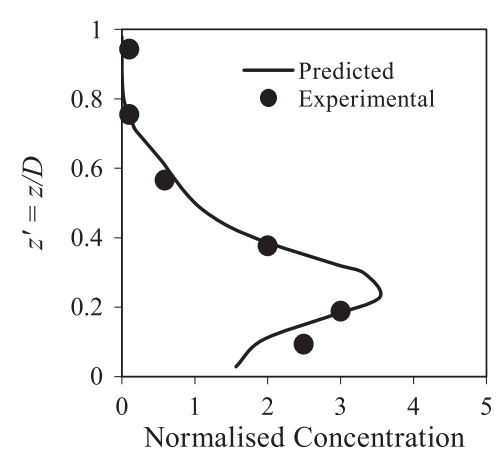

(b) Sand at $X=25 D$

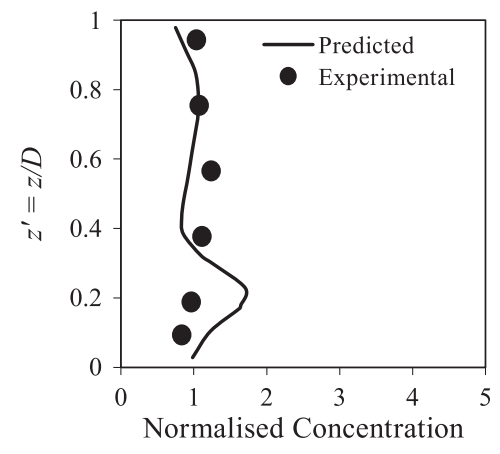

(e) Flyash at $X=25 D$

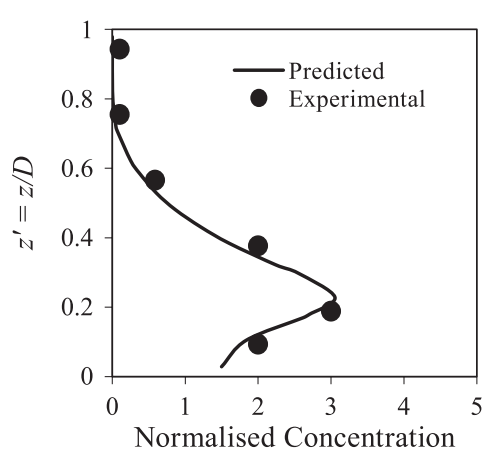

(c) Sand at $X=50 D$

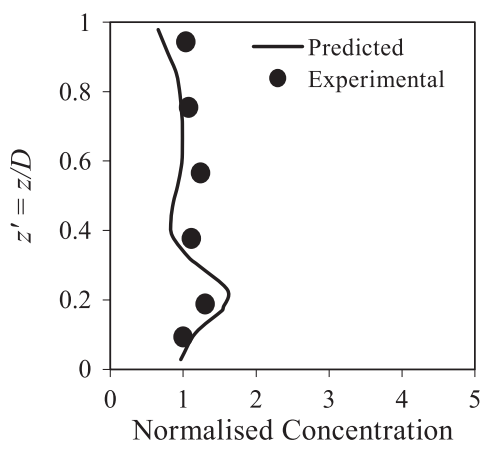

(f) Flyash at $X=50 D$

Fig. 13 Concentration distributions at $C_{\mathrm{vf}}=8.82 \%$ (sand:flyash $=70: 30$ ) and $V_{\mathrm{m}}=2.67 \mathrm{~m} / \mathrm{s}$ (Normalised Concentration for sand $\left.=\alpha_{\mathrm{s}}\left(z^{\prime}\right) / C_{\mathrm{ss}}\right)$ and Normalised Concentration for fly ash $\left.=\alpha_{\mathrm{f}}\left(z^{\prime}\right) / C_{\mathrm{f}}\right)$. 


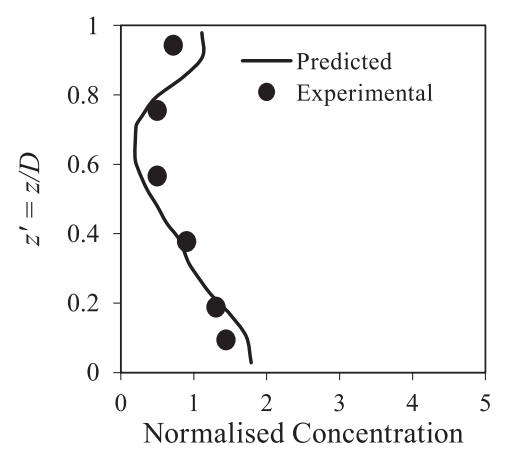

(a) Sand at $X=5 D$

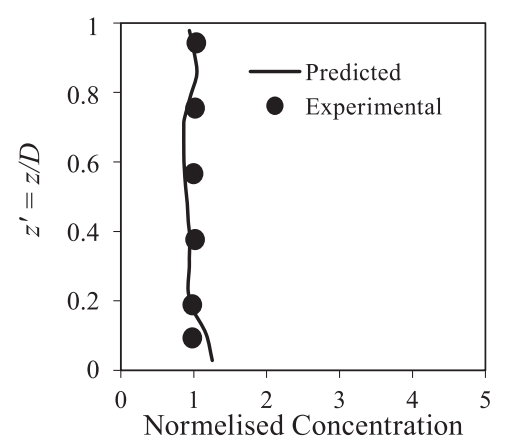

(d) Flyash at $X=5 D$

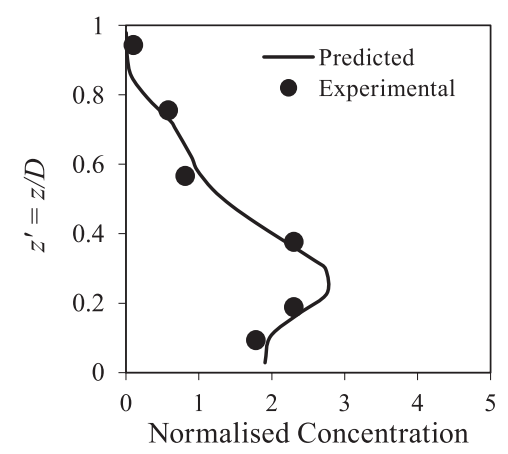

(b) Sand at $X=25 D$

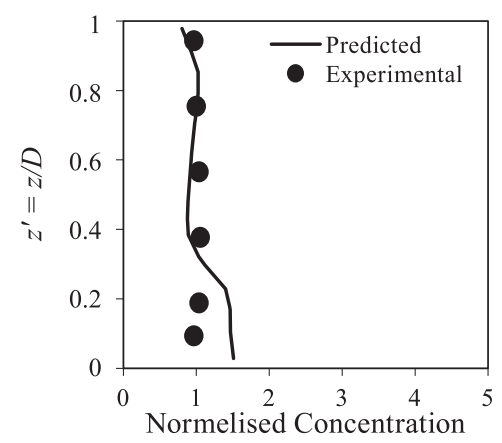

(e) Flyash at $X=25 D$

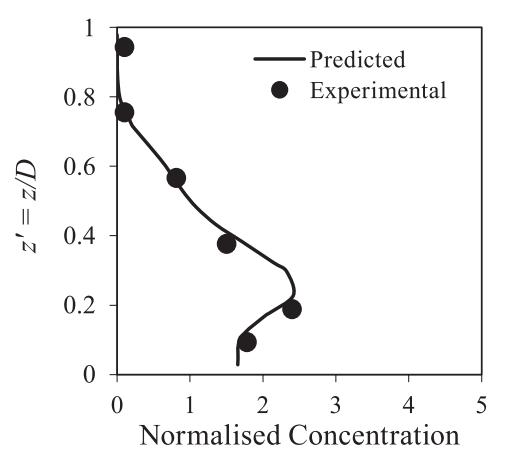

(c) Sand at $X=50 D$

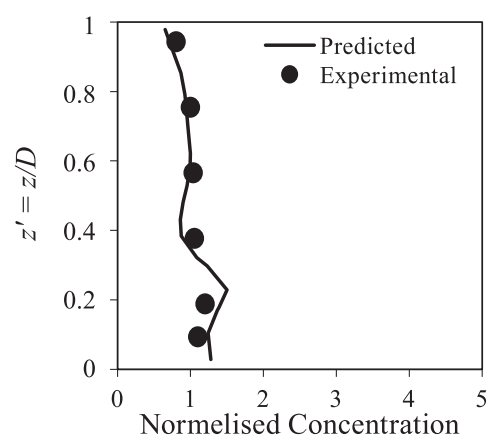

(f) Flyash at $X=50 D$

Fig. 14 Concentration distributions at $C_{\mathrm{vf}}=8.82 \%$ (sand:flyash $=70: 30$ ) and $V_{\mathrm{m}}=3.56 \mathrm{~m} / \mathrm{s}$ (Normalised Concentration for sand $\left.=\alpha_{\mathrm{s}}\left(z^{\prime}\right) / C_{\mathrm{ss}}\right)$ and Normalised Concentration for fly ash $\left.=\alpha_{\mathrm{f}}\left(z^{\prime}\right) / C_{\mathrm{f}}\right)$.

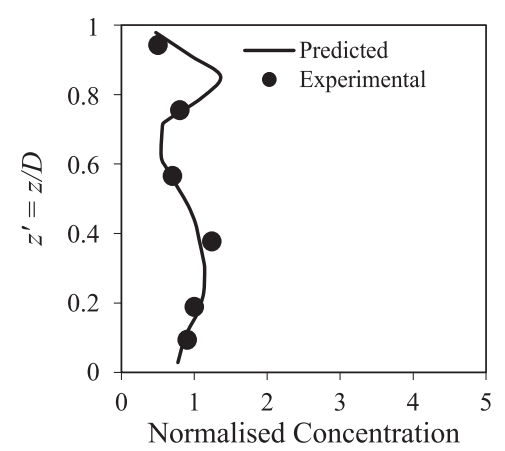

(a) Sand at $X=5 D$

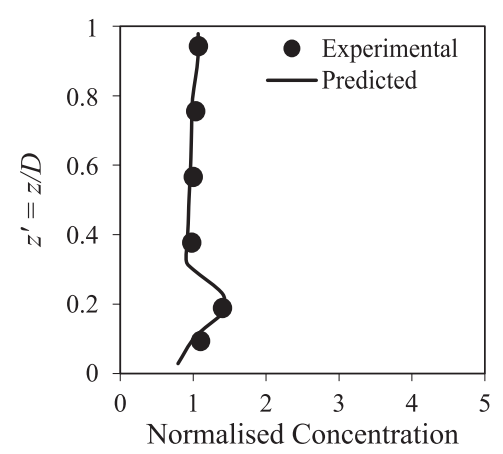

(d) Flyash at $X=5 D$

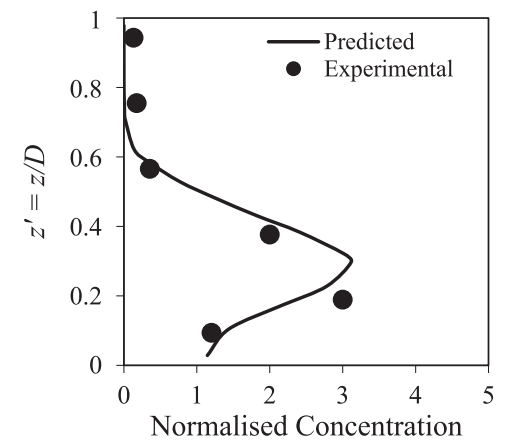

(b) Sand at $X=25 D$

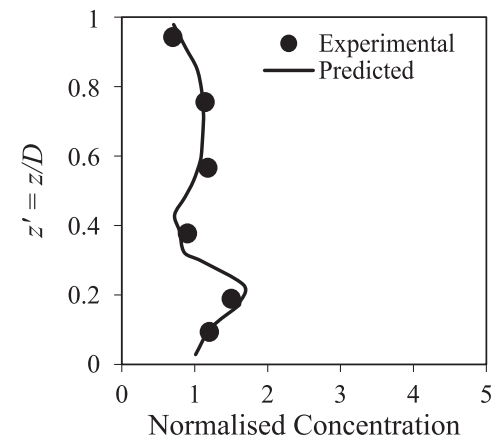

(e) Flyash at $X=25 D$

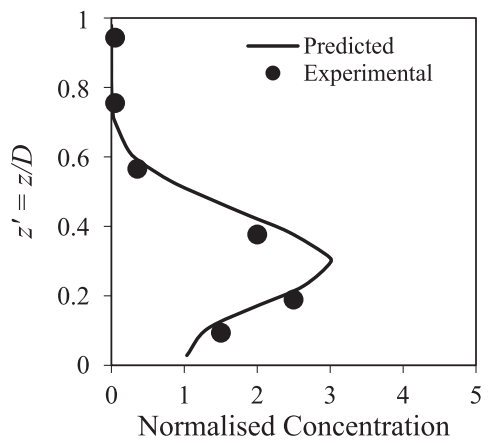

(c) Sand at $X=50 D$

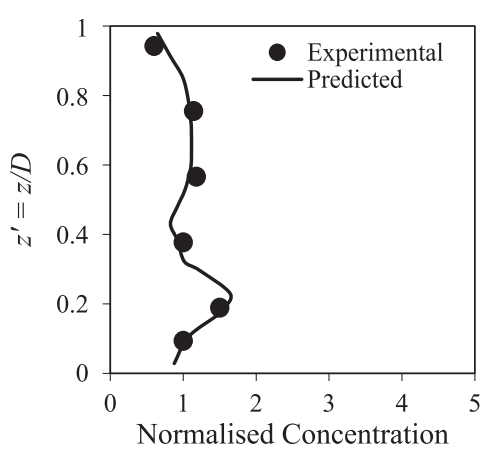

(f) Flyash at $X=50 D$

Fig. 15 Concentration distributions at $C_{\mathrm{vf}}=16.28 \%$ (sand:flyash $=70: 30$ ) and $V_{\mathrm{m}}=1.78 \mathrm{~m} / \mathrm{s}$ (Normalised Concentration for sand $\left.=\alpha_{\mathrm{s}}\left(z^{\prime}\right) / C_{\mathrm{ss}}\right)$ and Normalised Concentration for fly ash $\left.=\alpha_{\mathrm{f}}\left(z^{\prime}\right) / C_{\mathrm{f}}\right)$. 


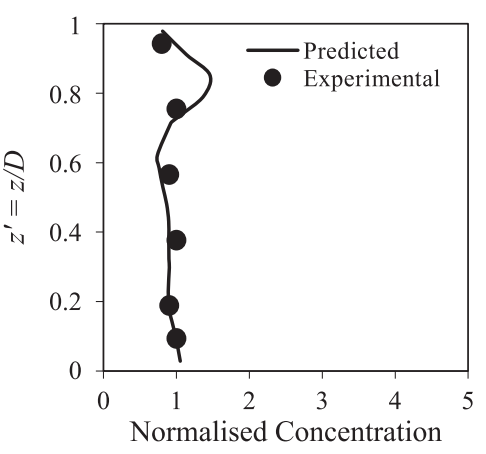

(a) Sand at $X=5 D$

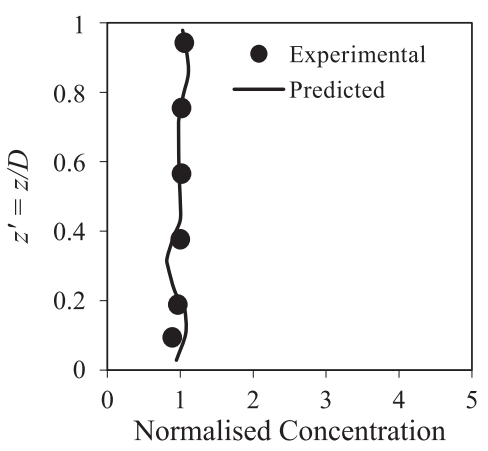

(d) Flyash at $X=5 D$

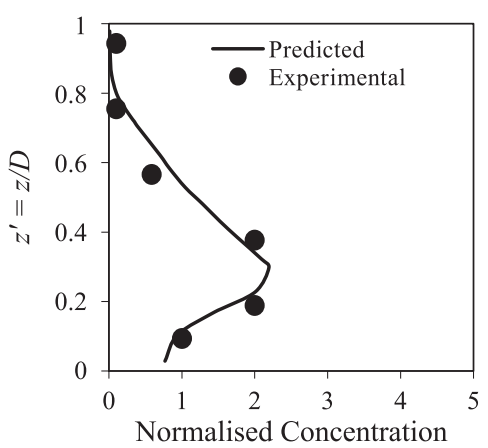

(b) Sand at $X=25 D$

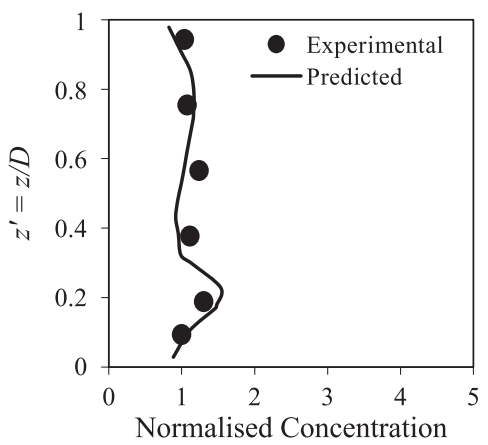

(e) Flyash at $X=25 D$

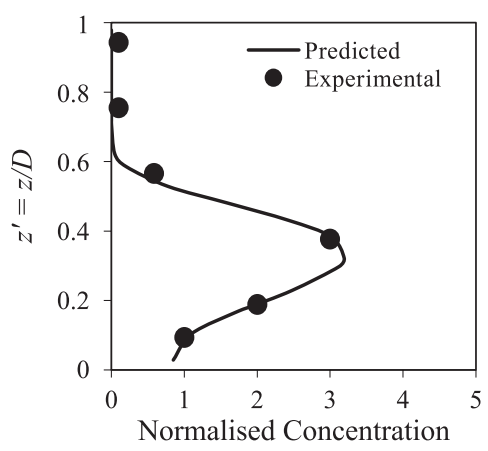

(c) Sand at $X=50 D$

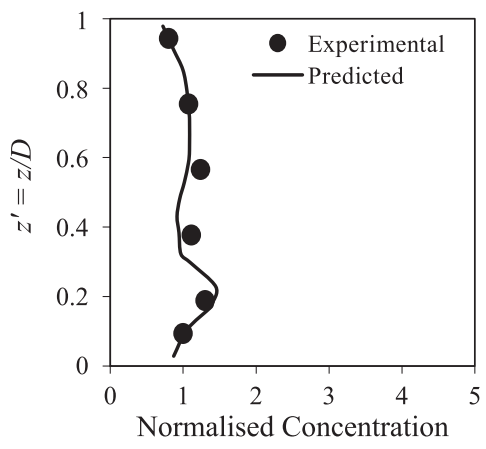

(f) Flyash at $X=50 D$

Fig. 16 Concentration distributions at $C_{\mathrm{vf}}=16.28 \%$ (sand:flyash $\left.=70: 30\right)$ and $V_{\mathrm{m}}=2.67 \mathrm{~m} / \mathrm{s}$ (Normalised Concentration for sand $\left.=\alpha_{\mathrm{s}}\left(z^{\prime}\right) / C_{\mathrm{ss}}\right)$ and Normalised Concentration for fly ash $\left.=\alpha_{\mathrm{f}}\left(z^{\prime}\right) / C_{\mathrm{f}}\right)$.

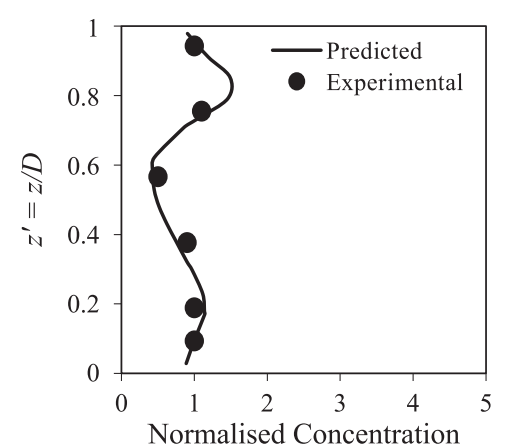

(a) Sand at $X=5 D$

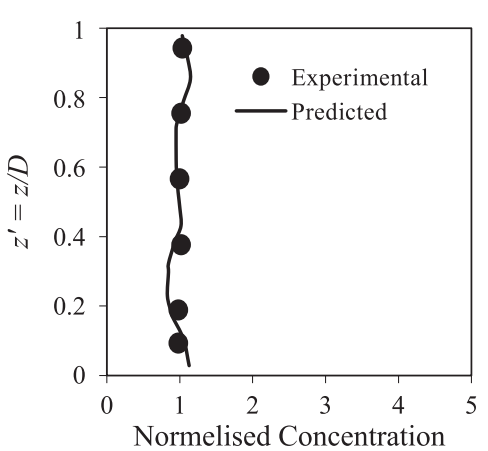

(d) Flyash at $X=5 D$

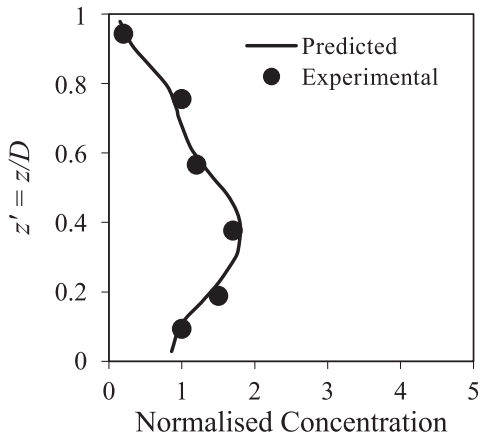

(b) Sand at $X=25 D$

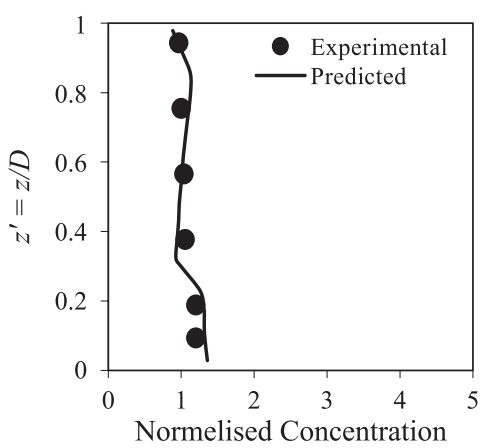

(e) Flyash at $X=25 D$

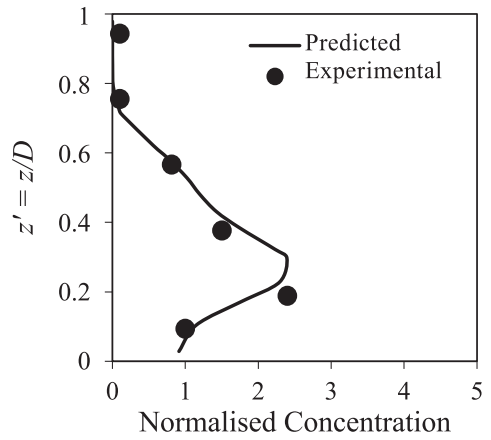

(c) Sand at $X=50 D$

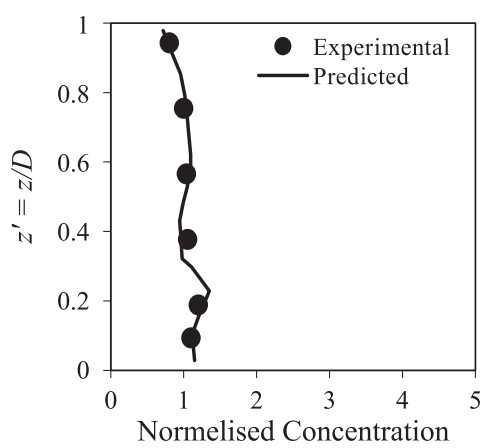

(f) Flyash at $X=50 D$

Fig. 17 Concentration distributions at $C_{\mathrm{vf}}=16.28 \%$ (sand:flyash $\left.=70: 30\right)$ and $V_{\mathrm{m}}=3.56 \mathrm{~m} / \mathrm{s}$ (Normalised Concentration for sand $\left.=\alpha_{\mathrm{s}}\left(z^{\prime}\right) / C_{\mathrm{ss}}\right)$ and Normalised Concentration for fly ash $\left.=\alpha_{\mathrm{f}}\left(z^{\prime}\right) / C_{\mathrm{f}}\right)$. 


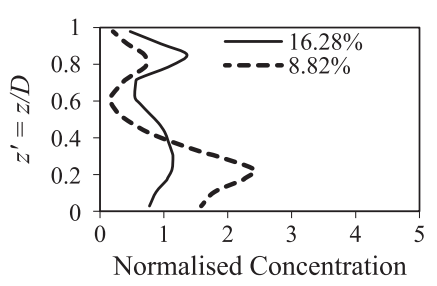

(a) $X=5 D, V_{\mathrm{m}}=1.78 \mathrm{~m} / \mathrm{s}$

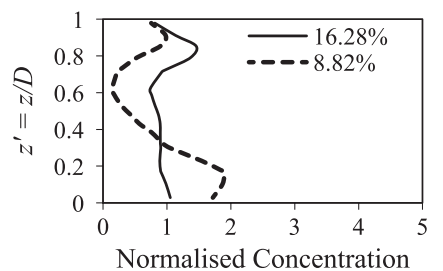

(d) $X=5 D, V_{\mathrm{m}}=2.67 \mathrm{~m} / \mathrm{s}$

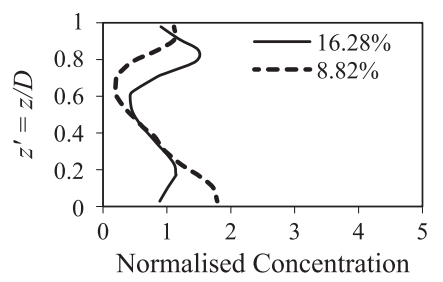

(g) $X=5 D, V_{\mathrm{m}}=3.56 \mathrm{~m} / \mathrm{s}$

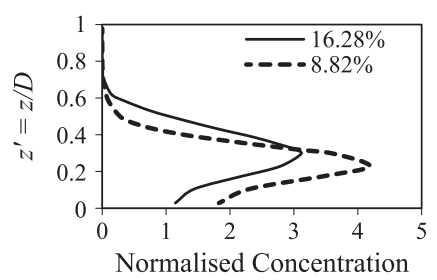

(b) $X=25 D, V_{\mathrm{m}}=1.78 \mathrm{~m} / \mathrm{s}$

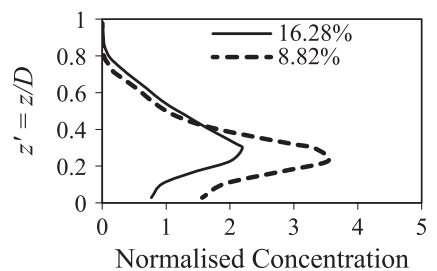

(e) $X=25 D, V_{\mathrm{m}}=2.67 \mathrm{~m} / \mathrm{s}$

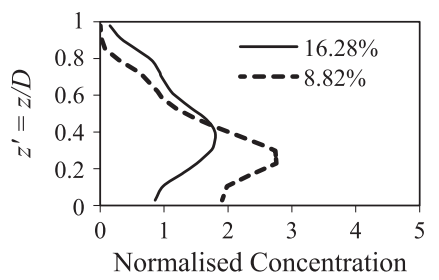

(h) $X=25 D, V_{\mathrm{m}}=3.56 \mathrm{~m} / \mathrm{s}$

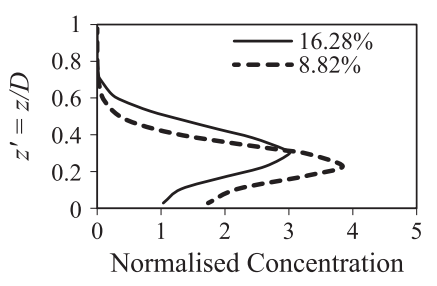

(c) $X=50 D, V_{\mathrm{m}}=1.78 \mathrm{~m} / \mathrm{s}$

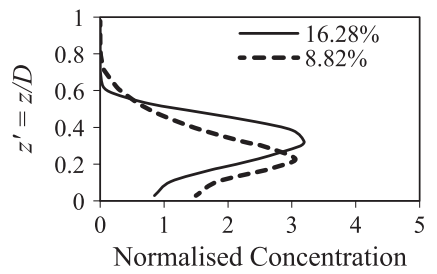

(f) $X=50 D, V_{\mathrm{m}}=2.67 \mathrm{~m} / \mathrm{s}$

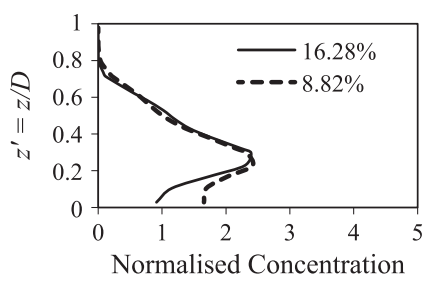

(i) $X=50 D, V_{\mathrm{m}}=3.56 \mathrm{~m} / \mathrm{s}$

Fig. 18 Predicted mid-vertical concentration profiles of sand at different $X$ and $V_{\mathrm{m}}$ for sand:flyash $=70: 30$ at $C_{\mathrm{vf}}=8.82 \%$ and $16.28 \%$ (Normalised Concentration $\left.=\alpha_{\mathrm{s}}\left(z^{\prime}\right) / C_{\mathrm{ss}}\right)$.

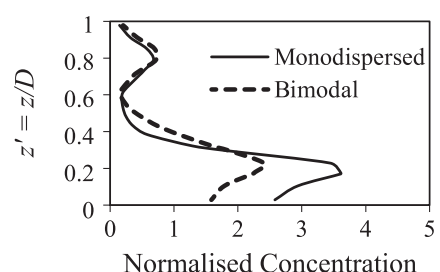

(a) $X=5 D, V_{\mathrm{m}}=1.78 \mathrm{~m} / \mathrm{s}$

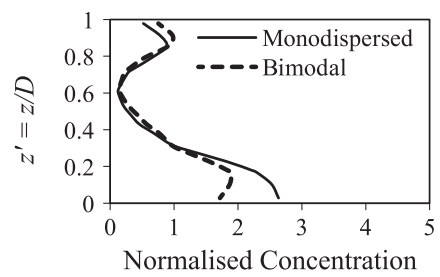

(d) $X=5 D, V_{\mathrm{m}}=2.67 \mathrm{~m} / \mathrm{s}$

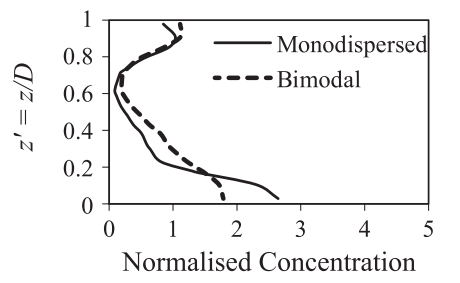

(g) $X=5 D, V_{\mathrm{m}}=3.56 \mathrm{~m} / \mathrm{s}$

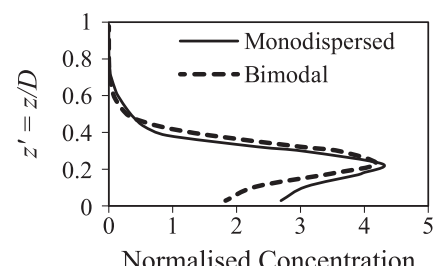

Normalised Concentration (b) $X=25 D, V_{\mathrm{m}}=1.78 \mathrm{~m} / \mathrm{s}$

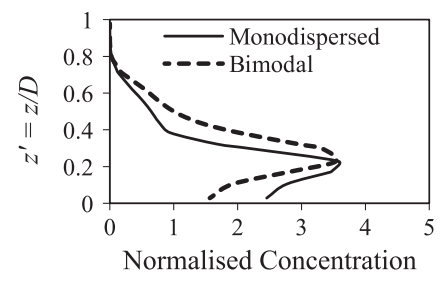

(e) $X=25 D, V_{\mathrm{m}}=2.67 \mathrm{~m} / \mathrm{s}$

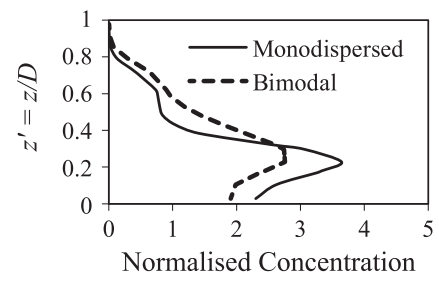

(h) $X=25 D, V_{\mathrm{m}}=3.56 \mathrm{~m} / \mathrm{s}$

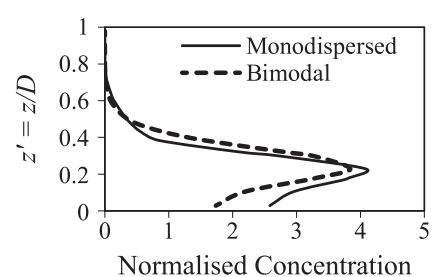

(c) $X=50 D, V_{\mathrm{m}}=1.78 \mathrm{~m} / \mathrm{s}$

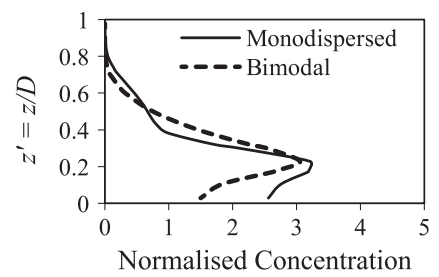

(f) Sand at $X=50 D, V_{\mathrm{m}}=2.67 \mathrm{~m} / \mathrm{s}$

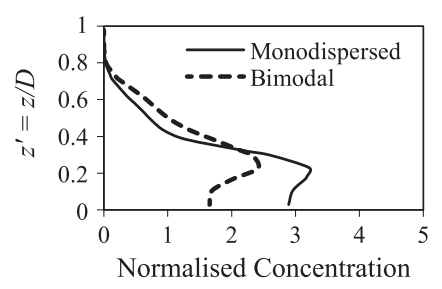

(i) $X=50 D, V_{\mathrm{m}}=3.56 \mathrm{~m} / \mathrm{s}$

Fig. 19 Predicted mid-vertical concentration profiles of sand in monodispersed and bimodal (sand:flyash $=70: 30)$ slurry at different $X$ and $V_{\mathrm{m}}$ at $C_{\mathrm{vf}}=8.82 \%$ (Normalised Concentration $\left.=\alpha_{\mathrm{s}}\left(z^{\prime}\right) / C_{\mathrm{ss}}\right)$. 


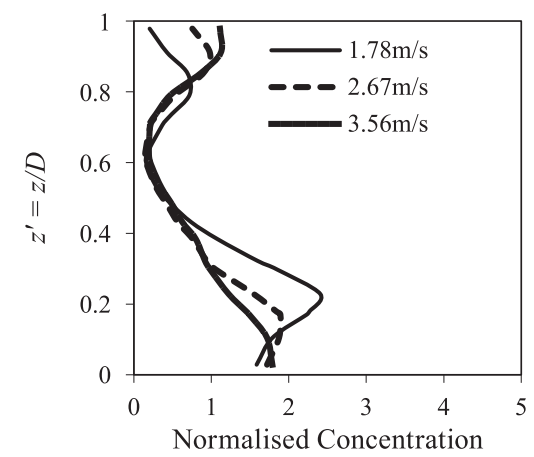

(a) $X=5 D$

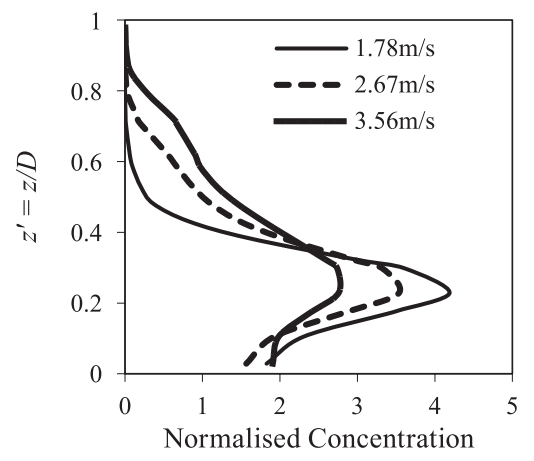

(b) $X=25 D$

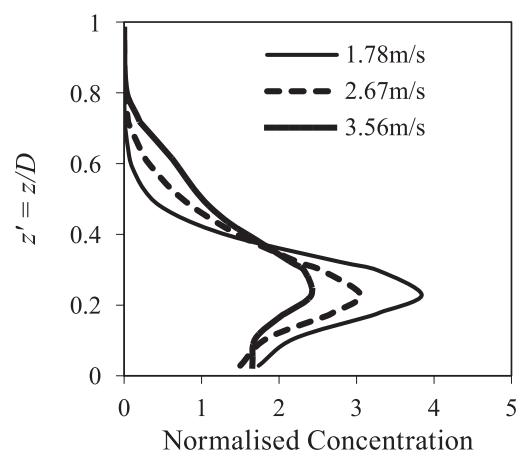

(c) $X=50 D$

Fig. 20 Concentration profile of sand for sand:flyash $=70: 30$ at $C_{\mathrm{vf}}=8.82 \%\left(\right.$ Normalised Concentration $\left.=\alpha_{\mathrm{s}}\left(z^{\prime}\right) / C_{\mathrm{ss}}\right)$.

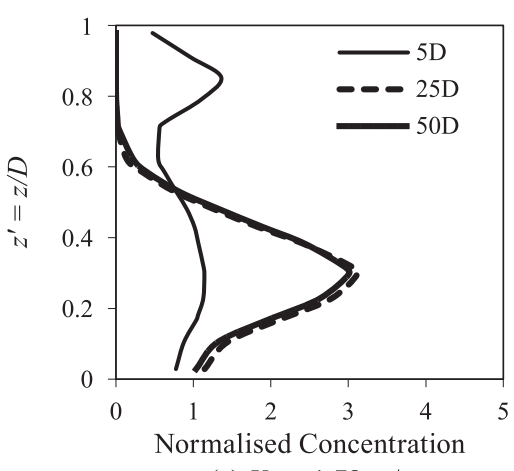

(a) $V_{\mathrm{m}}=1.78 \mathrm{~m} / \mathrm{s}$

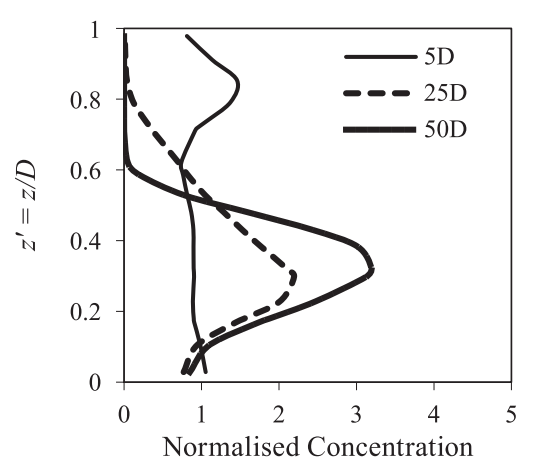

(b) $V_{\mathrm{m}}=2.67 \mathrm{~m} / \mathrm{s}$

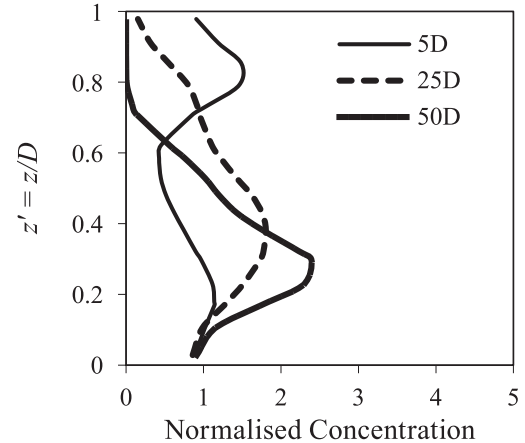

(c) $V_{\mathrm{m}}=3.56 \mathrm{~m} / \mathrm{s}$

Fig. 21 Concentration profiles of sand for sand:flyash $=70: 30$ at $C_{\mathrm{vf}}=16.28 \%$ (Normalised Concentration $\left.=\alpha_{\mathrm{s}}\left(z^{\prime}\right) / C_{\mathrm{ss}}\right)$.

\section{Nomenclature}

$D$

$d_{\text {mean }}$

$z$

$\alpha_{\mathrm{s}}$

$\alpha_{\mathrm{ss}} \quad$ concentration of silica sand (-)

$\alpha_{\mathrm{f}} \quad$ concentration of flyash (-)

$V_{\mathrm{ss}} \quad$ velocity of silica sand $(\mathrm{m} / \mathrm{s})$

$V_{\mathrm{f}} \quad$ velocity of flyash $(\mathrm{m} / \mathrm{s})$

$V_{\mathrm{w}} \quad$ velocity of water $(\mathrm{m} / \mathrm{s})$

$V_{\mathrm{sl}} \quad$ velocity of slurry $(\mathrm{m} / \mathrm{s})$

$V_{\mathrm{m}} \quad$ mean flow velocity $(\mathrm{m} / \mathrm{s})$

$C_{\mathrm{vf}} \quad$ efflux concentration of slurry (-)

$C_{\mathrm{ss}} \quad$ efflux concentration of silica sand (-)

$C_{\mathrm{f}} \quad$ efflux concentration of flyash (-)

$A$ pipe cross-sectional area $\left(\mathrm{m}^{2}\right)$

$\Delta p \quad$ pressure drop with reference to the velocity inlet $(\mathrm{Pa})$

$\rho_{\mathrm{m}} \quad$ density of the flowing fluid $\left(\mathrm{Kg} / \mathrm{m}^{3}\right)$

$g \quad$ acceleration due to gravity $\left(\mathrm{m} / \mathrm{s}^{2}\right)$

$\Delta h_{\mathrm{t}} \quad$ total head loss across the pipe bend (m) $k_{\mathrm{t}} \quad$ bend loss coefficients (-)

$k \quad$ turbulent kinetic energy $\left(\mathrm{m}^{2} / \mathrm{s}^{2}\right)$

$\varepsilon \quad$ turbulent dissipation rate $\left(\mathrm{m}^{2} / \mathrm{s}^{3}\right)$

$K_{\text {sf }} \quad$ inter-phase drag coefficient (-)

$\vec{v}_{\mathrm{s}} \quad$ velocity of solid phase $(\mathrm{m} / \mathrm{s})$

$\vec{v}_{\mathrm{f}} \quad$ velocity of fluid phase $(\mathrm{m} / \mathrm{s})$

$C_{\mathrm{L}} \quad$ lift coefficient taken as 0.5 in the present study (-)

$\nabla P_{\mathrm{s}} \quad$ solid pressure gradient $(\mathrm{Pa})$

$\nabla P \quad$ static pressure gradient $(\mathrm{Pa})$

$C_{\mathrm{vm}} \quad$ coefficient of virtual mass force taken as 0.5 in the present study $(-)$

$\tau_{\mathrm{f}} \quad$ stress tensor for fluid (Pa)

$\tau_{\mathrm{s}} \quad$ stress tensors for solid (Pa)

$\lambda_{\mathrm{s}} \quad$ bulk viscosity of the solids (Pa.s)

$d_{\mathrm{s}} \quad$ particle diameter put as $440 \mu \mathrm{m}$ for silica sand and $75 \mu \mathrm{m}$ for flyash $(\mu \mathrm{m})$

$g_{\mathrm{o}, \mathrm{ss}} \quad$ radial distribution function (-)

$\alpha_{\mathrm{s}, \max }$ static settled concentration measured as 0.52 and 0.50 for sand and flyash particles, respectively $(-)$

$\Theta_{\mathrm{s}} \quad$ granular temperature $(\mathrm{Pa})$

$e_{\mathrm{ss}} \quad$ restitution coefficient (-) 
$u_{\mathrm{f}} \mathrm{W}^{\mathrm{N}}$ - shear viscosity of fluid (Pa.s)

$\mu_{\mathrm{s}} \quad$ shear viscosity of solids (Pa.s)

$R \quad$ radius of curvature of pipe bend ( $\mathrm{mm})$

$r \quad$ internal radius of pipeline $(\mathrm{mm})$

$k_{\mathrm{s}} \quad$ pipe roughness $(\mathrm{mm})$

\section{References}

Ahmed M., Singh S.N., Seshadri V., Pressure drop in a long radius $90^{\circ}$ horizontal bend for the flow of multi-sized heterogeneous slurries, International Journal of Multiphase Flow, 1994 (21) 329-334.

Boothroyde J., Jacobs B.E.A., Jenkins P., Coarse particle hydraulic transport, Proceedings Hydrotransport, BHRA Fluid Engineering, Cranfield, Bedford, England, 6 (1979), 405-428.

FLUENT 6.3.26 User's Guide, Chapter 23: Modelling Multiphase Flows, Fluent Incorporation, USA, 2006.

Gidaspow D., Bezburuah R., Ding J., Hydrodynamics of circulating fluidized beds, kinetic theory approach in fluidization VII, Proc. 7th Engineering Foundation Conference on Fluidization, 1992.

Gopaliya M.K., Kaushal D.R., Analysis of Effect of Grain Size on Various Parameters of Slurry Flow through Pipeline Using CFD, Particulate Science and Technology: An International Journal, 33 (2015) 369-384.

Gopaliya M.K., Kaushal D.R., Modeling of sand-water slurry flow through horizontal pipe using CFD, J. Hydrol. Hydromech., 64 (2016) 261-272.

Gupta R., Singh S.N., Seshadri V., Migration of solid particles in the heterogeneous slurry flow through a $90^{\circ}$ bend, Indian Journal of Engineering and Material Science, 4 (1997) $10-20$.

Hayashi H., Sampei T., Oda S., Ohtomo S., Some Experimental Studies on Iron Concentrate Slurry Transportation in Pilot Plant, Proceedings of Hydrotransport, BHRA Fluid Engineering, Cranfield, Bedford, England, 7 (1980) D2.

Ito H., Pressure losses in smooth pipe bends, Journal of Basic Engineering, ASME, 82 (1960) 131-140.

Kaushal D.R., Thinglas T., Tomita Y., Kuchii S., Tsukamoto H., CFD Modeling for Pipeline Flow of Fine Particles at High Concentration, Int. J. of Multiphase Flow, 43 (2012) 85-100.

Kaushal D.R., Kumar A., Tomita Y., Kuchii S., Tsukamoto H., Flow of mono-dispersed particles through horizontal bend, Int. J. of Multiphase Flow, 52 (2013) 71-91.

Kazanskij B.H., Hinsch J., Influence of added fine particles on the flow structure and the pressure losses in sand-water mixture, Proceedings of Hydrotransport, BHRA Fluid Engineering, Colardo, USA, 3 (1974) 11-21.

Kumar A., Kaushal D.R., Kumar U., Bend Pressure Drop Experiments compared with FLUENT, Institution of Civil Engineers journal of Engineering and Computational Mechanics, Thomas Telford Publication London, 161 (2008) 35-42.

Kumar A., Experimental and CFD modeling of hydraulic and pneumatic conveying through pipeline, Ph.D. Thesis, Indian Institute of Technology Delhi, 2010.

Lun C.K.K., Savage S.B., Jeffrey D.J., Chepurniy N., Kinetic theories for granular flow: inelastic particles in couette flow and slightly inelastic particles in a general flow field, Journal of Fluid Mechanics, 140 (1984) 223-256.

Messa G.V., Malavasi S., Numerical Prediction of Particle Distribution of Solid-Liquid Slurries in Straight Pipes and Bends, Engineering Applications of Computational Fluid Mechanics, 8 (2014) 356-372.

Nasr-El-Din H., Shook C.A., Effects of $90^{\circ}$ bend on slurry velocity and concentration distribution, Journal of Pipelines, 6 (1987) 239-252.

Thinglas T., Kaushal D.R., Comparison of two dimensional and three Dimensional CFD Modeling of Invert Trap Configuration to be used in Sewer Solid Management, Particuology, 6 (2008a) 176-184.

Thinglas T., Kaushal D.R., Three Dimensional CFD Modeling for Optimization of Invert Trap Configuration to be used in Sewer Solid Management, Particulate Science and Technology, 26 (2008b) 507-519.

Verkerk C.G., Transport of Fly Ash Slurries. Proceedings of Hydrotransport, BHRA Fluid Engineering, Johannesburg, South Africa, 8 (1982) 307-316.

\section{Appendix A: Mathematical model}

Two-phase Eulerian model adopted in present research assumes that the slurry comprises solid "so" and fluid "fl". These phases are considered as separated but continuous and interpenetrating in such a way that $\alpha_{\mathrm{so}}+\alpha_{\mathrm{fl}}=100 \%$. These phases are made to satisfy continuity and momentum equations separately. Equations of fluid and solid phases were coupled using inter-phasial exchange coefficients and pressure. Different forces existing in the slurry flow are listed below.

\section{Body forces, $\rho \vec{g}$}

2. Drag force, $K_{\mathrm{sf}}\left(\vec{v}_{\mathrm{s}}-\vec{v}_{\mathrm{f}}\right)$

3. Lift force, $C_{\mathrm{L}} \alpha_{\mathrm{s}} \rho_{\mathrm{f}}\left(\vec{v}_{\mathrm{f}}-\vec{v}_{\mathrm{s}}\right) \times\left(\nabla \times \vec{v}_{\mathrm{f}}\right)$

4. Pressure gradient for solid phase, $\nabla P_{\mathrm{s}}$

5. Static pressure gradient, $\nabla P$

6. Virtual mass force: $C_{\mathrm{vm}} \alpha_{\mathrm{s}} \rho_{\mathrm{f}}\left(\vec{v}_{\mathrm{f}} \cdot \nabla \vec{v}_{\mathrm{f}}-\vec{v}_{\mathrm{s}} \cdot \nabla \vec{v}_{\mathrm{s}}\right)$

7. Viscous forces, $\nabla \cdot \boldsymbol{\tau}_{\mathrm{f}}$

The continuity equation (equation A1) and momentum equations (equations A2 and A3) need to be satisfied by each phase separately. These equations are coupled using exchange coefficients and pressure (equations A4 and A5).

Continuity equation:

$\nabla \cdot\left(\alpha_{\mathrm{t}} \rho_{\mathrm{t}} \vec{v}_{t}\right)=0$

Momentum equation for fluid phase:

$$
\begin{aligned}
& \nabla \cdot\left(\alpha_{\mathrm{f}} \rho_{\mathrm{f}} \vec{v}_{\mathrm{f}} \vec{v}_{\mathrm{f}}\right)=-\alpha_{\mathrm{f}} \nabla P+\nabla \cdot \boldsymbol{\tau}_{\mathrm{f}}+ \\
& \alpha_{\mathrm{f}} \rho_{\mathrm{f}} \vec{g}+K_{\mathrm{sf}}\left(\vec{v}_{\mathrm{s}}-\vec{v}_{\mathrm{f}}\right)+ \\
& C_{\mathrm{vm}} \alpha_{\mathrm{f}} \rho_{\mathrm{f}}\left(\vec{v}_{\mathrm{s}} \cdot \nabla \vec{v}_{\mathrm{s}}-\vec{v}_{\mathrm{f}} \cdot \nabla \vec{v}_{\mathrm{f}}\right) \\
& +C_{\mathrm{L}} \alpha_{\mathrm{s}} \rho_{\mathrm{f}}\left(\vec{v}_{\mathrm{f}}-\vec{v}_{\mathrm{s}}\right) \times\left(\nabla \times \vec{v}_{\mathrm{f}}\right)
\end{aligned}
$$


$b^{2} n^{2}$

$$
\begin{aligned}
& \nabla \cdot\left(\alpha_{\mathrm{s}} \rho_{\mathrm{s}} \vec{v}_{\mathrm{s}} \vec{v}_{\mathrm{s}}\right)=-\alpha_{\mathrm{s}} \nabla P-\nabla P_{\mathrm{s}}+\nabla \cdot \boldsymbol{\tau}_{\mathrm{s}}+ \\
& \alpha_{\mathrm{s}} \rho_{\mathrm{f}} \vec{g}+K_{\mathrm{fs}}\left(\vec{v}_{\mathrm{f}}-\vec{v}_{\mathrm{s}}\right)+ \\
& C_{\mathrm{vm}} \alpha_{\mathrm{s}} \rho_{\mathrm{f}}\left(\vec{v}_{\mathrm{f}} \cdot \nabla \vec{v}_{\mathrm{f}}-\vec{v}_{\mathrm{s}} \cdot \nabla \vec{v}_{\mathrm{s}}\right) \\
& +C_{\mathrm{L}} \alpha_{\mathrm{s}} \rho_{\mathrm{f}}\left(\vec{v}_{\mathrm{s}}-\vec{v}_{\mathrm{f}}\right) \times\left(\nabla \times \vec{v}_{\mathrm{f}}\right) \\
& \boldsymbol{\tau}_{\mathrm{s}}=\alpha_{\mathrm{s}} \mu_{\mathrm{s}}\left(\nabla \vec{v}_{\mathrm{s}}+\nabla \vec{v}_{\mathrm{s}}\right)+\alpha_{\mathrm{s}}\left(\lambda_{\mathrm{s}}-\frac{2}{3} \mu_{\mathrm{s}}\right) \nabla \cdot \vec{v}_{\mathrm{s}} I
\end{aligned}
$$

and

$$
\boldsymbol{\tau}_{\mathrm{f}}=\alpha_{\mathrm{f}} \mu_{\mathrm{f}}\left(\nabla \vec{v}_{\mathrm{f}}+\nabla \vec{v}_{\mathrm{f}}\right)
$$

Bulk viscosity of solids $\lambda_{\mathrm{s}}$ is proposed by Lun et al. (1984) as:

$$
\lambda_{\mathrm{s}}=\frac{4}{3} \alpha_{\mathrm{s}} \rho_{\mathrm{s}} d_{\mathrm{s}} g_{\mathrm{o}, \mathrm{ss}}\left(1+e_{\mathrm{ss}}\right)\left(\frac{\Theta_{\mathrm{s}}}{\pi}\right)^{\frac{1}{2}}
$$

Radial distribution function $g_{\mathrm{o}, \mathrm{ss}}$ is proposed by Gidaspow et al. (1992) as:

$$
g_{\mathrm{o}, \mathrm{ss}}=\left[1-\left(\frac{\alpha_{\mathrm{s}}}{\alpha_{\mathrm{s}, \max }}\right)^{\frac{1}{3}}\right]^{-1}
$$

Granular temperature $\Theta_{\mathrm{s}}$ is taken into account in the mathematical model by using transport equations as described by Kaushal et al. (2013).

\section{Turbulence closure for the fluid and solid phase:}

Turbulent quantities for the fluid and solid phase are calculated using RNG $k-\varepsilon$ model and Tchen's theory, respectively, supplemented by additional terms accounting interfacial turbulent momentum transfer as described by Kaushal et al. (2013).

\section{Wall function:}

The region very near to the walls needs special attention. In this region, the flow parameters have very high gradients. This region is dealt with a very fine boundary layer meshing. Standard wall functions along with RNG $k-\varepsilon$ model is used. Wall functions are semi-empirical formulas used for reducing the difficulty in calculation and better results close to the wall.

\section{Boundary Conditions}

There are three boundaries available in the given flow domain namely the inlet boundary, the wall boundary and the outlet boundary. Constant concentration and flow velocity were considered at the inlet boundary. A $0.15 \mathrm{~mm}$ of pipe wall roughness is adopted during simulation. Wall boundary conditions are adopted phase-wise: no slip for liquid phase and specularity co-efficient of 0.5 for solid phase. Pressure outlet boundary condition is adopted at the outlet boundary where mixture pressure is mentioned.

\section{Solution Process and Convergence Criteria}

The convergence criteria is decided on the basis of proper residual values for different parameters at the end of computation for better results. In the present study a residual value of $10^{-3}$ is set as convergence criteria. The solution was converged and computations were stopped in 1475 iterations for slurry flow with sand:flyash $=70: 30$ at $V_{\mathrm{m}}=3.56 \mathrm{~m} / \mathrm{s}$ and $C_{\mathrm{vf}}=16.28 \%$ through pipe bend. The actual values of the residuals at convergence for mass, $u$, $v$ and $w$ components of water, sand and flyash in $x, y$ and $z$ directions, $k$ and $\varepsilon$ for water and volume fractions of sand and flyash were $2.9024 \times 10^{-4}, 9.1087 \times 10^{-5}, 5.5728 \times 10^{-6}$, $3.0933 \times 10^{-6}, 1.1206 \times 10^{-5}, 3.3552 \times 10^{-6}, 2.4197 \times 10^{-6}$, $1.2064 \times 10^{-5}, 4.6818 \times 10^{-6}, 3.1317 \times 10^{-6}, 2.9304 \times 10^{-4}$, $9.9960 \times 10^{-4}, 3.5810 \times 10^{-4}$ and $2.6986 \times 10^{-4}$, respectively.

\section{Author's short biography}

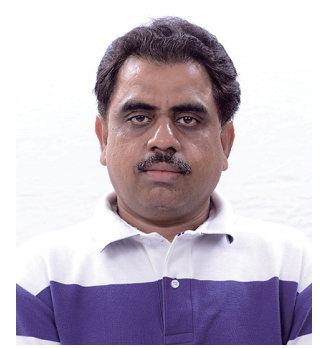

\section{Deo Raj Kaushal}

Dr. D.R. Kaushal was trained to be a slurry pipeline designer during his Ph.D. at IIT Delhi and Post Doctoral Research at KIT Japan. He has been an Associate Professor of Hydraulics in Water Resources Engineering Section of Civil Engineering Department at IIT Delhi since 2004. He has visited KIT Japan and KCT Japan as visiting Professor. During his teaching and postdoctoral research, he has carried out several research and consultancy projects. He has worked with several mining, mineral-processing and production companies, either through direct consultation or through collaboration with other companies or research organizations. 


\section{Author's short biography}

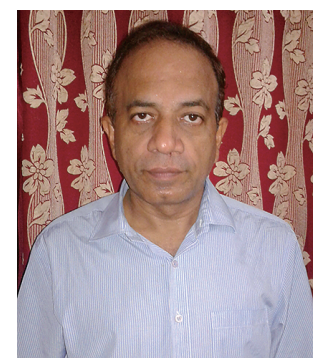

\section{Arvind Kumar}

Dr. A. Kumar is currently Professor in Mechanical Engineering Department at YMCA University of Science and Technology, Faridabad (Haryana) India. He obtained his B.Tech. (Mechanical Engg.) from AMU, Aligarh and M.Tech. and PhD From Indian Institute of Technology Delhi, India. He is having 25 years Teaching, Research and Industrial experience. His areas of specialization include Computational Fluid Dynamics, Multiphase flow, Slurry flow in pipeline system. Energy efficiency and energy management in thermal system, heat transfer, Refrigeration and Air-conditioning.

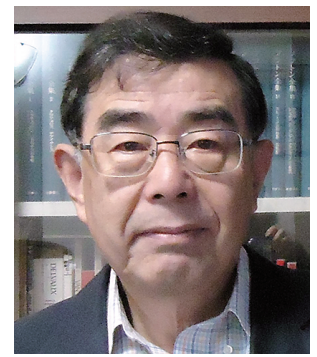

\section{Yuji Tomita}

Prof. Yuji Tomita was born in Dalian, China in 1942. From 1970 to 2006, he has been working at Kyushu Institute of Technology in the mechanical engineering department. He taught fluid mechanics and powder technology. His research topics include fluid drag reduction, pipeline conveying of solids by pneumatic, slurry and capsule method, performance characteristics of blow-tank solids conveyor, rotary and injection feeders, flushing phenomena of fine powder by compression and vibration, and air entrainment by free falling powder jet.

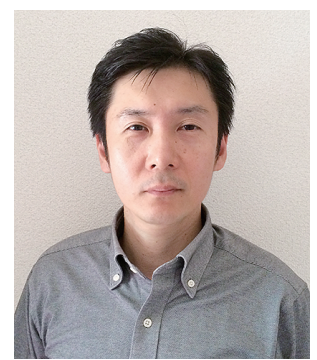

\section{Shigeru Kuchii}

Prof. Shigeru Kuchii is a Professor from Department of Creative Engineering, National Institute of Technology (NIT), Kitakyushu College. He received the B.S, M.S and $\mathrm{Ph} \mathrm{D}$. degrees all in Mechanical Engineering from Kyushu Institute of Technology, Japan. He is working on research topic in Powder Technology, Mechanical Engineering, Mechatronics and Information Technology.

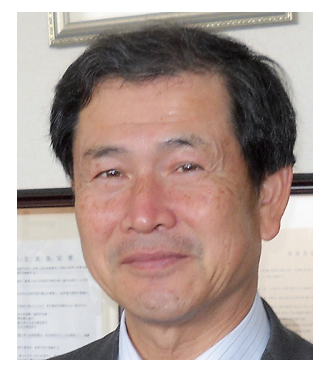

\section{Hiroshi Tsukamoto}

Prof. Hiroshi Tsukamoto is the President of National Institute of Technology, Kitakyushu College. After receiving the Ph.D. degree from the University of Tokyo, Tokyo, Japan, he was a Lecturer in the Department of Mechanical Engineering, University of Tokyo, and an Associate Professor, a Professor in the Department of Mechanical Engineering, and a Professor of biological functions and engineering, Kyushu Institute of Technology, Kitakyushu, Japan, where he has been a Professor Emeritus since 2009. Dr. Tsukamoto is a fellow of The Japan Society of Mechanical Engineers, and a member of The Engineering Academy of Japan. 